\title{
LA REBELIÓN DE MANCO INKA Y VILCABAMBA EN TEXTOS ANDINOS COLONIALES: OTROS MATERIALES PARA SU ESTUDIO
}

\author{
MANCO INKA'S REBELLION AND VILCABAMBA IN COLONIAL ANDEAN \\ TEXTS: OTHER MATERIALS FOR THEIR STUDY
}

josé Luis Martínez C. A

Se presenta un conjunto de textos andinos, en soportes visuales y de cantares de memoria, acerca de la sublevación de Manco Inka en el Cuzco y el posterior período en Vilcabamba, con la muerte de varios de los inkas. Se propone que estos materiales muestran dos momentos en la construcción de relatos sobre estos eventos. El primero, contemporáneo a los acontecimientos, el segundo, posterior y como parte de una memoria andina. Los textos circularon en los sistemas andinos de comunicación y muestran grados importantes de autonomía discursiva, así como de las tensiones entre los distintos bandos existentes.

Palabras clave: Manco Inka, Vilcabamba, Relatos coloniales, Rebelión.

This article presents a set of andean texts, in visual media and in songs of memory, about Manco Inka' uprising in Cuzco and the subsequent period in Vilcabamba, with the death of several of the inkas. It is suggested that these materials show two moments in the elaboration of stories about these events. The first moment is contemporary to the events, while the second, later moment is part of an Andean memory. The texts circulated in the Andean systems of communication and show important degrees of discursive autonomy. They also reveal the tensions between the different existing factions.

Keywords: Manco Inka, Vilcabamba, Colonial narratives, Rebellion.

\section{TEXTOS CANÓNICOS}

Como se sabe, en 1536 Manco Inka inició una rebelión asediando a los españoles asentados en la antigua capital inka, rompiendo el pacto establecido hasta ese momento, que había creado un incómodo co-gobierno (Lamana 2001, Roy 2013). Tras ser derrotado en la fortaleza de Saqsaywaman, Manco se vio obligado a levantar el cerco al Cuzco y retirarse lentamente por el valle sagrado, hasta llegar finalmente a la ciudad de Vilcabamba, ubicada en el piedemonte amazónico, en una zona que, ahora se conoce, tenía un importante valor simbólico, económico y estratégico (Roy 2013, Bauer et al. 2015, Decoster \& Ziólkowski 2016). Simultáneamente, varios de sus ejércitos y de otros grupos de tropas andinas se enfrentaban a los españoles en diversos lugares de los Andes, como Lima, Xauxa y el Qollasuyu (Guillén 2005, Hemming 2005, Platt et al. 2006). Ayudados por diversos señoríos andinos, como los wankas y los cañaris, además de una parte de la misma élite inkaica liderada por Paullu Inka, los españoles lograron finalmente controlar la rebelión. Hacia 1544, fecha del asesinato de Manco Inka en Vilcabamba, los esfuerzos del denominado estado neo-inka

A José Luis Martínez C., ORCID: 0000-0001-5276-8036, Universidad de Chile. Centro de Estudios Culturales Latinoamericanos, Departamento de Ciencias Históricas. E-mail: jomarcer@u.uchile.cl 
habían sido relativamente contenidos (Lamana 2001, Guillén 2005, Roy 2013, Ziólkowski 2014). La situación de resistencia se prolongó hasta 1572, cuando el virrey Francisco de Toledo desencadenó la campaña definitiva destinada a capturar al entonces último Inka, Thupaq Amaru, quien fue posteriormente ejecutado por decapitación en la misma ciudad del Cuzco. Cuatro Inkas alcanzaron a gobernar en Vilcabamba: Manco Inka, Sayri Thupaq, Titu Kusi Yupanqui y Thupaq Amaru (Guillén 1979, Roy 2013).

Es difícil, a estas alturas, magnificar aún más la importancia que tuvo la rebelión contra los españoles para todos los grupos involucrados en los diferentes bandos. No solo el cerco de las ciudades del Cuzco y Lima (las más importantes de la época), sino también la muerte de varios encomenderos a manos de destacamentos indígenas (Hemming 2005) y el retorno apresurado de Almagro desde Chile, quedaron en la memoria de los testigos europeos de ese momento. Los testimonios españoles dan cuenta de cómo en el imaginario colonizador se identificaron, descubrieron o supusieron, contemporáneamente a esos hechos, otras múltiples empresas indígenas insurgentes. Ya fuera el movimiento anti cristiano conocido como Taki onqoy en las vecindades de Arequipa, cuyas posibles vinculaciones con los inkas asentados en Vilcabamba preocupaban ampliamente (Albornoz 1967 [i158...?], Ramos 1992, Millones 2007, Roy 2010); la sublevación de los chichas, atacamas y otros grupos del sur del altiplano andino, dirigidos por Viltipoco (Lorandi 1988, Sánchez \& Sica 1994), o la misma existencia de Vilcabamba, desde donde cada cierto tiempo salían capitanes inkas a atacar a los aliados de los europeos; todas esas situaciones sirvieron para que, ya fueran los mismos europeos o sus aliados andinos, presentaran probanzas de servicios, argumentaran méritos o escribieran cartas a las autoridades respectivas. Las negociaciones con los sublevados, o su posterior represión, también fueron una cantera de relatos de proezas, ${ }^{1}$ de peticiones de reconocimiento a los esfuerzos de una $\mathrm{u}$ otra autoridad o funcionario, o intentos de construir martirologios y, por esa vía, obtener los primeros santos del naciente virreinato (Bauer et al. 2014). Se conoce, así, un material documental relativamente abundante que registró esos años turbulentos.

Es difícil aceptar que, desde la perspectiva de los andinos de cualquiera que hayan sido los bandos en disputa, esos acontecimientos y el período mismo no hubieran tenido igualmente una enorme relevancia y no hayan circulado relatos y versiones sobre lo ocu- rrido. Sin embargo, los textos escritos o dictados por andinos son pocos; conocemos el relato de Titu Cusi Yupanqui (1570), redactado poco antes de su asesinato en Vilcabamba, al que debieran sumarse la crónica de Betanzos (1551), que cubre parcialmente el período, y la de Murúa (1590), dado que en ambas hubo una importante participación de algunos linajes cuzqueños en su elaboración. Posteriormente, Guaman Poma (1616) escribió y dibujó sobre algunos episodios de esas luchas. También Garcilaso (1617) escribió un relato más tardío sobre esos acontecimientos.

Más abundantes y de primera mano son los muchos testimonios, incluidos en diversos pleitos y procesos judiciales, en los cuales declararon diferentes participantes (véase, por ejemplo, Guillén 2005, Bauer et al. 2014). Todo ello queda restringido, sin embargo, ya sean los autores como Guaman Poma o los testigos indígenas en juicios y probanzas, al ámbito de la escritura alfabética; a los controles de un tipo de registro que era propio a la sociedad dominante y que imponía una determinada lógica sobre el orden narrativo (pasadopresente), sobre los actores de los que se debía escribir (personajes, "héroes", autoridades; todas personas individuales y no actores colectivos) y, sobre todo, de una escritura sometida a los controles de un determinado tipo de registro que traducía los testimonios propiamente andinos a categorías o conceptos europeos de tiempo, acontecimiento y gobernantes. ${ }^{2}$

\section{OTROS RELATOS ANDINOS}

Hay otras fuentes andinas en las que aparecen referencias a diversos acontecimientos de lo ocurrido durante aquellos años. Por ejemplo, en las transcripciones de khipus usados en probanzas y relaciones hechas por algunos señores andinos que participaron en uno u otro de los bandos (Pärssinen \& Kiviharju 2004). Estos relatos priorizan a veces informaciones sobre enfrentamientos entre bandos andinos que involucraron, además de los cuzqueños, a otros señoríos andinos, como los wankas, ${ }^{3}$ y narran los acontecimientos desde un punto de vista no europeo: "Después vinieron del Cuzco Yangue Yupangui Ynga a destruir [a] los guancas dici[e]ndo que ayudaban al marqués y peleamos con ellos y matáronnos 88 yndios y llevaron 121 yndios. Y los que escaparon bibos fueron 1345 yndios de g[u]erra" (Guacrapaucar en Pärssinen \& Kiviharju 2004: 164, cursivas del autor). 
En las cuerdas de los khipus de la parcialidad de Urin Wanka se registraron al menos 12 batallas contra Manco Inka o alguno de sus capitanes; y los khipucamayoq anotaron que en ellas habían perdido al menos 372 "indios de guerra" y 173 mujeres en las batallas, sin contar la gente capturada por los inkas rebeldes que sumaban 285 entre hombres y mujeres (Guacrapaucar en Pärssinen \& Kiviharju 2004: 163-166). El recuento realizado en la década de 1560 por los señores de la parcialidad de Hatun Wanka es aún más impresionante. Se anotaron batallas entre miles de hombres por cada lado, una y otra vez; los ejércitos wankas fueron llevados a combatir a las tropas no solo en Vilcabamba, sino a rescatar al marqués Francisco Pizarro del cerco de la ciudad de Lima y para ayudar a sofocar los alzamientos de otros capitanes inkas en lugares como Ayavire, Bombón, Tarama y Comas. Sus registros abarcan varios años de luchas y también de exacciones, robos y arbitrariedades cometidas por los españoles (Sulicache en Pärssinen \& Kiviharju 2004: 203-229).

Los khipus fueron un eficiente sistema inkaico de registro y comunicación antes de la llegada de los europeos, de modo que no es de extrañar que en ellos se hayan anotado los acontecimientos y se hayan construido unas memorias que permitieron recordar lugares, nombres de capitanes de cada bando y número de personas muertas o perdidas, además de los productos robados o destruidos.

Se trata, al mismo tiempo, de un tipo de registros que podemos calificar como autónomos en un doble carácter. Por una parte, ellos funcionaban al interior de las sociedades andinas, con sus propias categorías conceptuales y lenguajes, aun dentro de la nueva condición colonial y en diálogo con esta misma, puesto que buscaban contar o explicar también a los europeos lo sucedido a las poblaciones andinas. En este sentido, fueron independientes de los relatos escritos europeos de la época, conservando sus propios principios (los acontecimientos descritos no están ordenados temporalmente en una secuencia, por ejemplo; y se registran a hombres y mujeres, o actores colectivos). Por otra parte, fueron también autónomos porque respondieron a intereses locales, de las autoridades tradicionales y sus comunidades afectadas.

La pregunta que surge de inmediato es qué ocurrió con los otros sistemas de registro y comunicación existentes en los Andes, de los que sabemos también su existencia, como las manifestaciones músico-coreográficas (cantares, bailes, representaciones públicas), los qeros o el arte rupestre. ¿En ellos también se registró algún tipo de información?, ¿fueron soportes para las memorias andinas?, ¿tuvieron igualmente ciertos grados de autonomía?, ¿qué decían y qué saberes y relatos construyeron? A ellos está dedicado este trabajo.

\section{TEXTOS ANDINOS CONTEMPORÁNEOS CON LA REBELIÓN}

Durante su estadía en Ollantaytambo, Manco Inka mandó hacer una pintura de sus armas. Aunque este acto no fue registrado en los documentos europeos, sí pasó a formar parte de un saber andino que permitió, años más tarde, que Guaman Poma (1616: f. 406) lo describiera como parte de los hechos de esa época: "y mandó retratarse el dicho Mango Inga y a sus armas en una peña grandísima para que fuese memoria”. Esta pintura es conocida y subsiste hasta la actualidad (Falcón 2015). Se encuentra en un lugar conocido actualmente como Inkapintay, en una pared rocosa que enfrenta el camino que viene del Cuzco, es decir, que debía ser vista $\mathrm{o}$ advertida por los andinos que llegaban al lugar $\mathrm{y}$ por los españoles que intentaban tomar la plaza (fig. 1).

Destaca la inmediatez temporal del registro visual. Es totalmente contemporáneo con los acontecimientos (Cummins 2004: 184), mostrando la capacidad de la élite inkaica de reaccionar y de enunciar sus posiciones, en sus propios conceptos. La pintura rupestre formaba parte de los sistemas de registro y comunicación empleados por los inkas para entregar mensajes políticos de importancia (Berenguer 2013). Así lo atestigua otra pintura, muy anterior, mandada hacer por Wiraqocha Inka para recordar su victoria sobre los chankas cuando estos mantenían cercada la ciudad del Cuzco y, al mismo tiempo, hacer pública su valentía, que contrastaba con la "cobardía” de su padre, Yawar Wak’aq Inka. Un cóndor con las alas plegadas, dándole la espalda a la ciudad como huyendo de ella, representó la actitud derrotista, en tanto que otro cóndor, esta vez con las alas desplegadas y en actitud agresiva, representó al Inka defensor de la ciudad; aparecía "feroz, con las alas abiertas, como que iba volando a hacer alguna presa" (Garcilaso 1991 [1609]: 306. Véase también Falcón 2013: 59). Y en un lugar muy alejado de la capital inka, en las tierras altas al sur del altiplano andino, conocidas hoy como puna de Atacama (en Argentina), hay un gran muro, identificado 


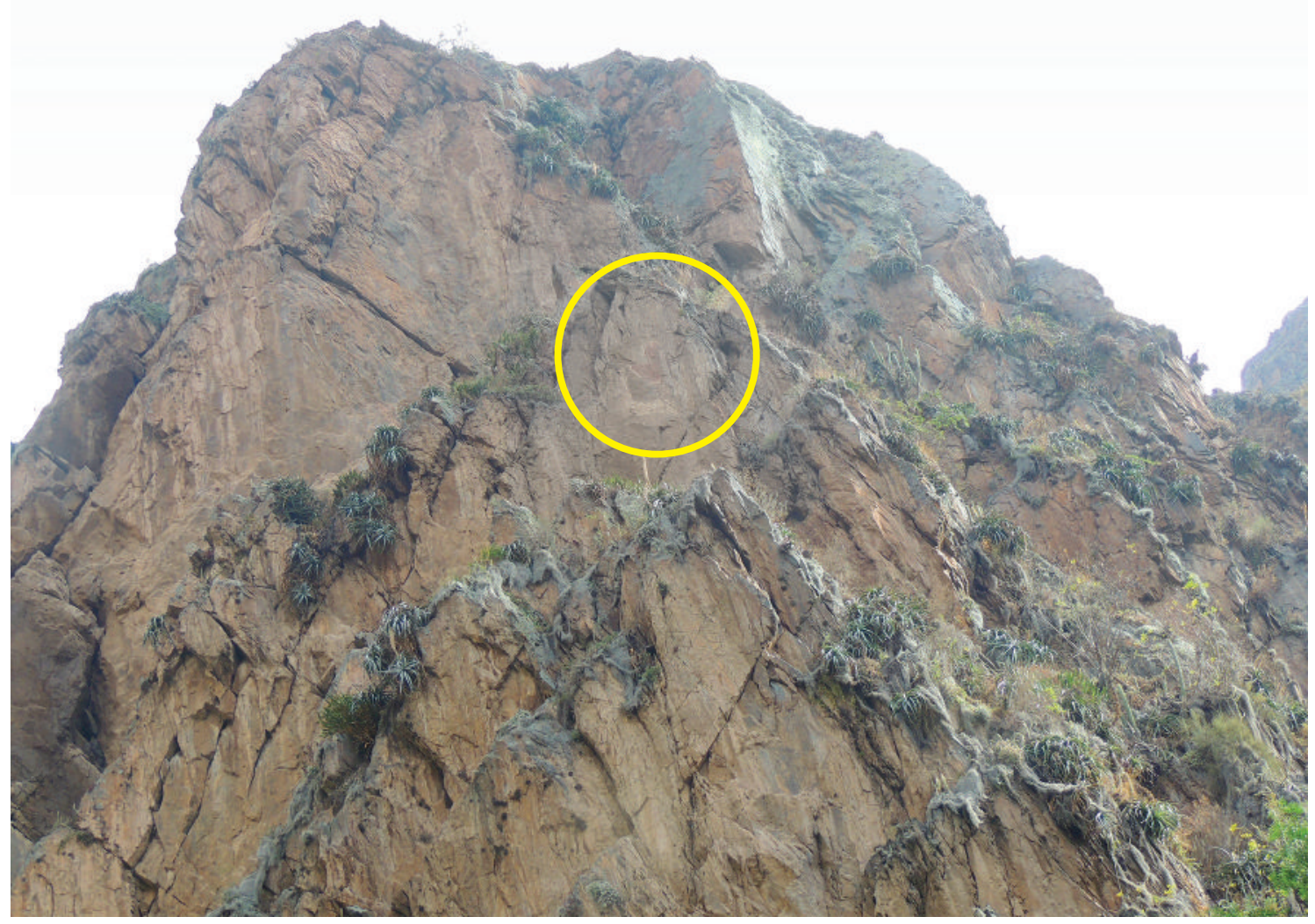

Figura 1. Inkapintay, a la entrada de Ollantaytambo. (Fotografía del autor). Figure 1. Inkapintay, at the entrance of Ollantaytambo. (Photograph by the author).

como "panel Boman", que muestra lo que los arqueólogos han interpretado como ejércitos inkas en lo que podría ser una conmemoración de alguna victoria o acuerdo político alcanzado con los grupos locales (Ruiz \& Chorolque 2007). Tanto la pintura de Ollantaytambo como la del panel Boman tienen elementos estilísticos que las vinculan, como la representación humana (del Inka y de los soldados) que se hace a partir de sus "armas"; el mismo conjunto simbólico fue usado aquí y allá, y consistía en la representación de la túnica o unku, del chuku o casco, y de una lanza (fig. 2).

Representaciones similares han sido encontradas en otros lugares del Tawantinsuyu, como en los sitios de Banderayoq y K'echuqaqa (Departamento del Cuzco), donde igualmente aparece una figura humana representada por su traje, casco y lanza (Berenguer 2013). Se trataba de un sistema visual que transmitía mensajes políticos (entre otros), codificado y conocido probablemente por muchos grupos andinos, muy anterior a la conquista hispana. Así, en un contexto político nuevo para los inkas, como lo fue la invasión europea y la pérdida de su capital, en un ambiente en el que los parámetros culturales habituales no siempre servían para comprender lo que ocurría, el Inka "mandó pintar" algo que probablemente para él y su gente era un acto esencial de reafirmación de su autoridad y del dominio simbólico que aún ejercía. Es un acto autónomo, que no fue recogido por las fuentes europeas y que muestra una voluntad de simbolizar un espacio como parte de los rituales andinos de la guerra y la confrontación.

Recientemente se encontró una vasija cerámica decorada, en la unidad arquitectónica $\mathrm{N}^{\circ} 5$, en el sitio de Espíritu Pampa, parte del complejo arqueológico de Vilcabamba (Bauer et al. 2015, Fonseca 2016). La vasija estaba en el piso de un edificio cuyo techo estaba destruido, con bastante probabilidad, como resultado 


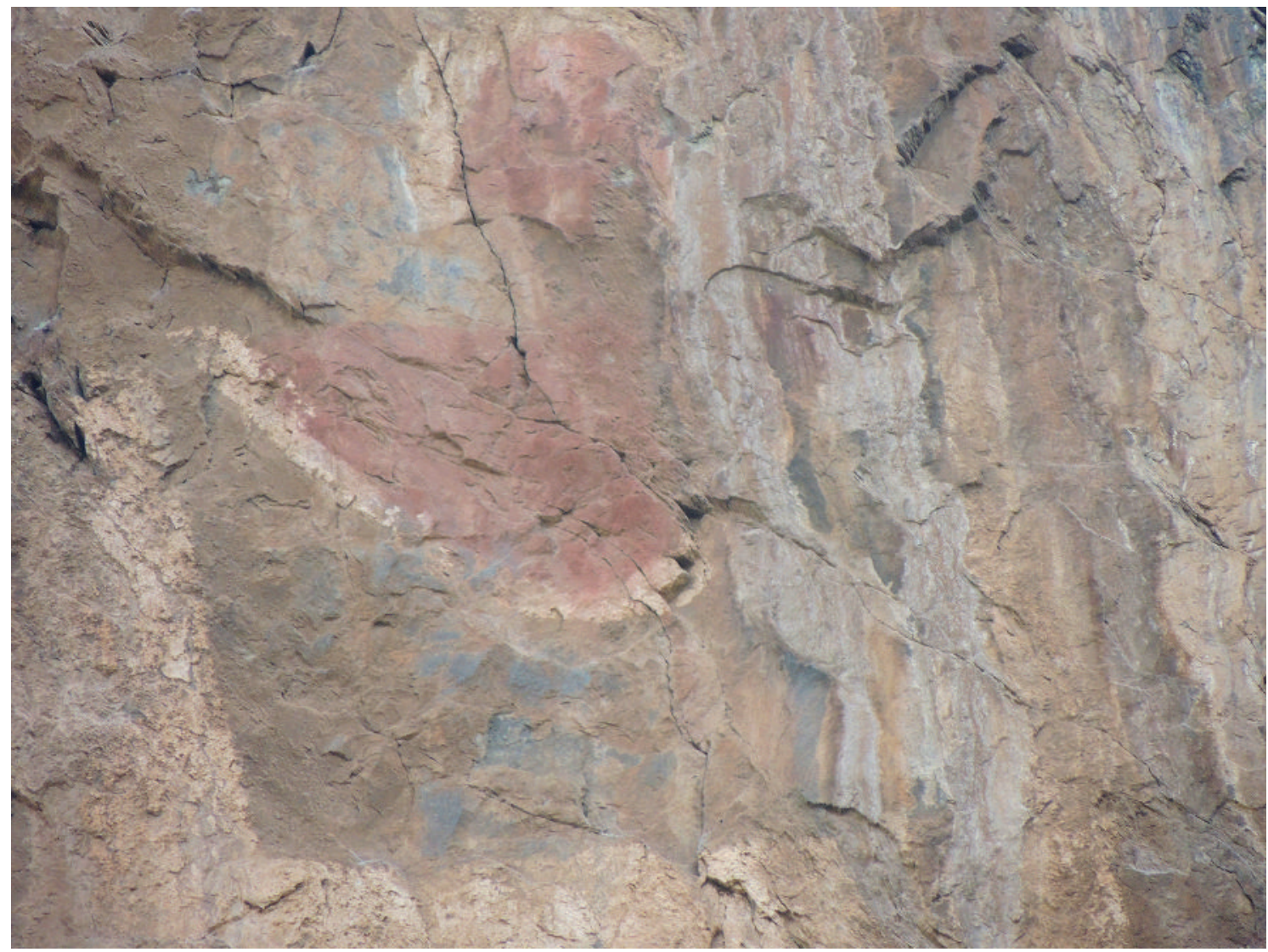

Figura 2. Inkapintay. Detalle con la figura y armas de Manco Inka. (Fotografía del autor). Figure 2. Inkapintay. Detail with the figure and weapons of Manco Inka. (Photograph by the author).

de un proceso ritual ejecutado por la misma población inkaica que había resistido hasta allí a los europeos. ${ }^{4}$ El recipiente tiene su superficie externa decorada con escenas de enfrentamiento entre jinetes europeos y tropas andinas, algunas de las cuales también se enfrentan mutuamente (fig. 3a y 3b). Me alargaré en su descripción y análisis, tanto por lo temprano de este texto visual como porque parece compartir determinados modos de representaciones visuales que pueden ser identificados a lo largo de todo el período colonial, tanto en el arte rupestre como en los qeros y paqchas. ${ }^{5}$

De acuerdo con Artzi et al. (2019), la escena está compuesta por 39 seres humanos y 57 animales, ubicados en un ambiente de selva. Por su procedencia y temática puede afirmarse que se trata de un texto andino elaborado en el centro mismo de la resistencia inka y contemporáneo a ese contexto de resistencia y luchas anticoloniales. ${ }^{6}$ Este texto muestra además varios rasgos diagnósticos que permiten identificar la vasija como parte de los estilos cerámicos Inka prehispánicos (Barraza 2012). Los autores postulan que no se trata de la representación de un evento particular, sino de una proposición política (una prefiguración del triunfo sobre los europeos) que, al igual que la pintura rupestre de Inkapintay, usó lenguajes visuales propios de las sociedades andinas de la época para elaborar una reflexión autónoma acerca de los sucesos de la instalación colonial y de las luchas andinas. Del análisis de esta escena los autores destacan varios conjuntos figurativos. El primero, los españoles; el segundo, los indígenas involucrados en el enfrentamiento. Finalmente, uno de entidades divinas compuesto por dos grupos de grandes serpientes (posiblemente amarus) de cuyas cabezas de felino surge un arcoíris. Se trata de entidades divinas que están acompañadas por varios insectos como arañas y moscas, utilizadas frecuentemente en rituales adivinatorios en los que 

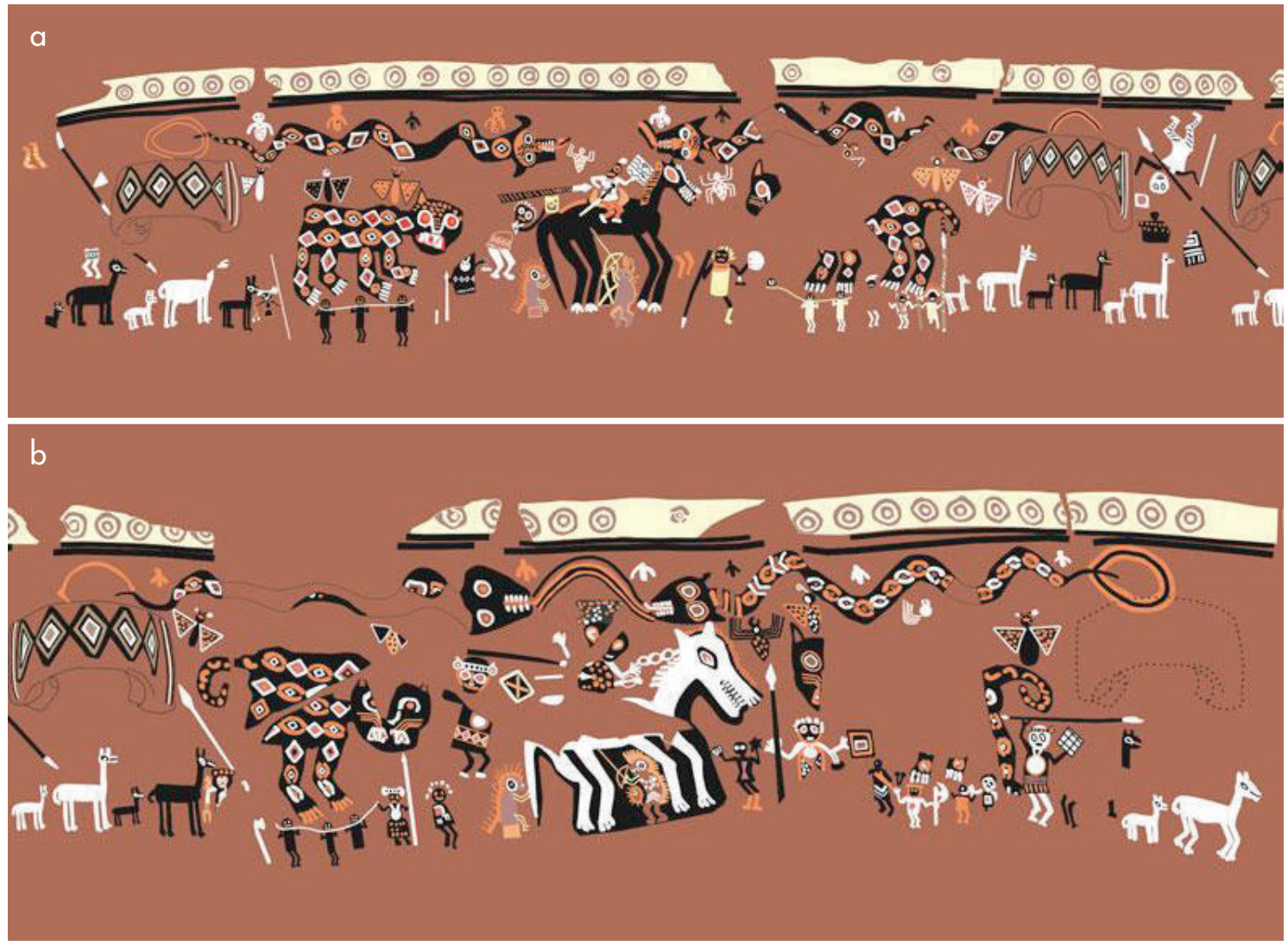

Figura 3a y b. Dibujo de la vasija encontrada en el sitio de Espíritu Pampa (Artzi et al. 2019: 161). Figure 3a and $b$. Sketch of the vessel found in the site Espíritu Pampa (Artzi et al. 2019: 161).

participaban las autoridades andinas. Dado que esta estructura narrativa se encuentra con posterioridad en los qeros y paqchas en los que se representaron episodios de la expansión del Tawantinsuyu y las luchas contra los chankas y los antis (Martínez et al. 2016), me atrevo a proponer que se trata de un modo andino de construir las narraciones, en el cual participan tanto los humanos, como también wak'as y otras divinidades, además de aves, insectos y plantas.

¿Qué principios narrativos se siguieron para construir estos conjuntos?, ¿ cómo se representó visualmente a unos y otros? Se debe destacar que, mientras los animales, seres divinos y humanos ya eran representados figurativamente en la cerámica Inka y eran por lo tanto conocidos para los andinos, los españoles y sus objetos debieron ser elaborados para construir una imagen que fuera reconocible fácilmente para todo observador. Como en cualquier narrativa, sea oral o no, los ciclos de relatos requieren de la construcción de determinadas figuras narrativas (los personajes), que tienen características determinadas; rasgos que permiten identificarlos, o realizan acciones propias de su condición.

El primer conjunto, el de los españoles, me parece notable. Quiero destacar aquí al menos tres aspectos que considero centrales: a) las figuras ecuestres; b) los dos europeos que aparecen muertos o vencidos; y c) los objetos que portan. Los dos jinetes montan caballos con extremidades flectadas, lo que para las convenciones visuales inkaicas supone presentar movimiento, formando un conjunto que se mira mutuamente. Los caballos muestran unos agresivos dientes y un rasgo que resulta muy sugerente: en sus patas tienen tres dedos o lo que semeja pezuñas de camélidos. Esta es una primera llamada de atención a que el proceso intelectual andino puesto en juego para construir estas imágenes, sin previos referentes conocidos, pudiera haber sido autónomo respecto de las proposiciones visuales europeas importadas a América. Refuerza esta 


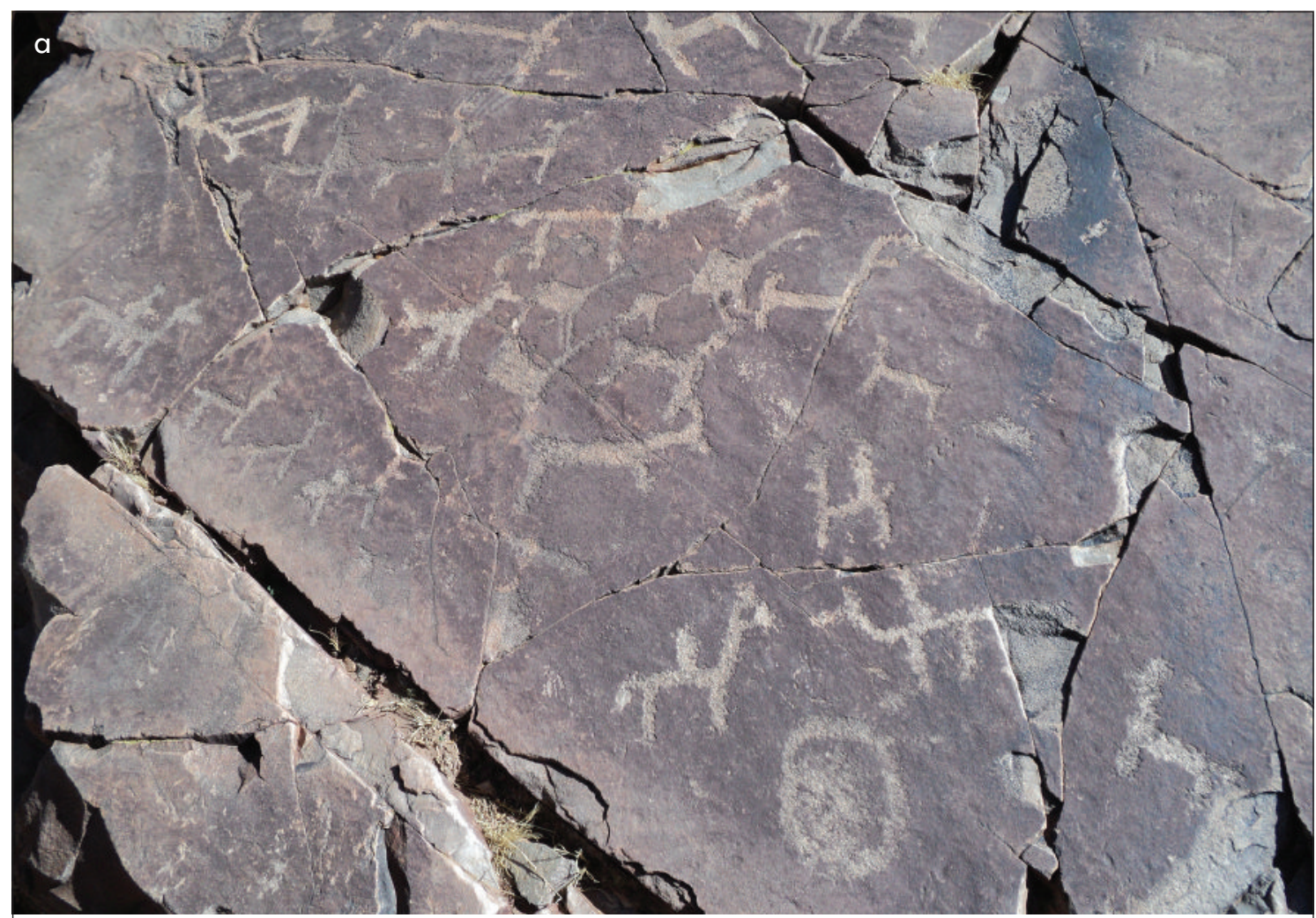

b

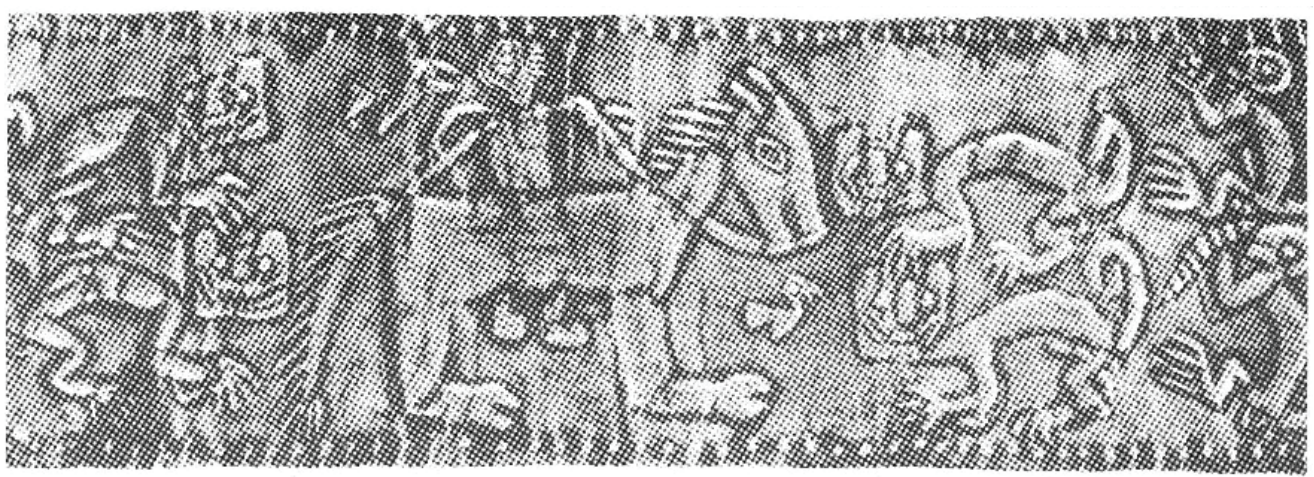

Figura 4: a) camélidos "resignificados" en Zapagua (Noroeste de Argentina. Fotografía gentileza de Anahí Re); b) jinete español en sobre relieve. El caballo tiene pezuñas de camélido (en Bird 1962, fig. 41c, apud Gallardo et al. 1990). Figure 4: a) "resignified" camelids in Zapagua (Northwestern Argentina. Photograph courtesy of Anahí Re); b) spanish horseman in relief. The horse has camelid hooves (in Bird 1962, fig. 41c, by Gallardo et al. 1990).

proposición el análisis de lo que se ha llamado figura ecuestre en el arte rupestre, esto es, un jinete sobre una cabalgadura, la cual parece haberse construido como un nuevo significante visual en los Andes a partir de la unión de otros signos preexistentes: los camélidos y los antropomorfos. Existen muchos registros rupestres en distintos lugares de los Andes, en especial en lo que fue el Qollasuyu, que muestran cómo se fueron superponiendo los antropomorfos sobre los camélidos para ir construyendo la figura ecuestre (fig. 4). Una cronología 
relativa propone que se trataría de grabados y pinturas realizados en el siglo xvi (Martínez \& Arenas 2015).

Dos figuras, parcialmente fragmentadas, han sido identificadas por Artzi et al. como españoles muertos, con los pies hacia arriba y a uno de los jinetes lo está alcanzando una flecha. Si bien no conozco antecedentes anteriores al siglo xvi para este tipo de representación de la derrota, se trata de un modo visual que perduró al menos hasta el siglo xviII en los qeros y paqchas coloniales. Lo notable es que se trata de la única pieza conocida en la cual se representó la muerte de europeos a manos andinas (los otros casos corresponden a enemigos andinos de los inkas). Desde esta perspectiva, es una proposición política fuerte. Finalmente, los objetos culturales europeos. En primer lugar, quiero resaltar las espadas y lanzas. La figura ecuestre, a la que me referí, se aprecia con frecuencia en el arte rupestre de gran parte del sur andino, probablemente contemporáneo a la elaboración de esta vasija. Está compuesta por uno o más jinetes a caballo, portando igualmente espadas o lanzas; objetos agudos, punzantes. En el sitio de Anccomayo, en la Provincia Espinar (Departamento de Cuzco), hay un registro rupestre que muestra una escena de enfrentamiento entre un jinete y un hombre a pie (Hostnig 2004, fig. 7d). El jinete aparece atravesando con su lanza o un objeto alargado al infante. Como este, se encuentran muchos otros en distintos lugares. Este conjunto visual sobre la alteridad europea surge, así, caracterizado por rasgos de violencia anti indígena, una figura narrativa que también perduró durante el Período Colonial.

Artzi et al. (2019: 165) llaman también la atención sobre otro objeto en manos españolas. Un rectángulo con signos que aparenta ser una página con escritura alfabética y una posible cruz, lo que la transformaría en un texto religioso. En un contexto de violencia y de posible derrota europea, si se sigue la proposición de estos autores, la escritura oficiaría entonces como otra arma, un instrumento de conquista que debe ser derrotado. Nuevamente, se trata del único caso que conozco con una representación política tan explícita acerca de la escritura como instrumento de dominación, derivada posiblemente de la posición de resistencia de Vilcabamba.

Respecto del segundo conjunto, el de los andinos combatientes, el detallado análisis de Artzi et al. señala que se trataría de tropas cuyos trajes y armas los muestran como pertenecientes a los cuatros suyos, además de incluir la presencia de algunos capitanes cuzqueños
(2019: 165-168). Esto pareciera reiterar las declaraciones de Titu Cusi Yupanqui, en su Instrucción acerca de que en la sublevación de Manco Inka participaban ejércitos de todo el Tawantinsuyu: "para que todos estos, cada suyo por sy, juntasen la gente necesaria para el efeto" (1992 [1570]: 41). Sería así, una proposición política (no aislamiento) y simbólica (la unidad de los suyus) la que estaría representada a través de esta diversidad de personajes.

El tercer conjunto está compuesto por divinidades o entidades vinculadas, únicamente andinas. Artzi et al. (2019: 172) describen detalladamente a los cuatro felinos que están ubicados en los costados de los jinetes y parecen participar de la batalla, puesto que los encuadran. Los autores destacan, asimismo, la presencia de dos arcoíris que surgen de grandes amarus con cabezas felínicas y están ubicados sobre ambos jinetes (Artzi et al. 2019: 169). Entre sus muchas significaciones, los arcoíris permitían expresar un momento de cambios fundantes. Aparentemente es uno de los sentidos que tienen en los qeros y diversos relatos andinos (Martínez C. 2012), cuestión también señalada por Artzi et al. $¿$ Quiere decir esto que su presencia es un reconocimiento explícito a ese momento de cambios y crisis que acarreó la instalación del proyecto colonial y a la rebelión de Manco Inka?

Una tercera versión de esos tiempos de violencia fue presentada durante la realización del primer Corpus Christi en el Cuzco, en el año 1555, y fue hecha igualmente en soportes y lenguajes propiamente andinos. Esa vez fue uno de los colaboradores de los españoles, don Francisco Chillche, cacique del grupo de los cañaris. ${ }^{7}$ Chillche recurrió a tres tipos diferentes de soportes y textos visuales para hacer pública su versión sobre los sucesos de la lucha de Manco Inka por expulsar a los españoles del imperio. Pintó sus andas con imágenes que, desgraciadamente, no quedaron registradas, y señaló: "Estas cuatro pinturas de mis andas son cuatro batallas de indios y españoles en las cuales me hallé en servicio dellos" (Garcilaso 1962 [1617]: 108). Además, se vistió con ropajes que evidenciaban una actitud guerrera y belicosa. Bajo la manta con la cual se acercó hasta el estrado en el que estaba el Santísimo Sacramento, llevaba otra, anudada a la cintura, "como hemos dicho que se la ciñen cuando quieren pelear o hacer cualquiera otra cosa de importancia" Garcilaso 1962 [1617]: 108. Finalmente, exhibió la cabeza cortada y guardada en una bolsa, de uno de los capitanes inkas 
a quien el mismo Chillche había derrotado y decapitado durante el cerco de la ciudad del Cuzco y la defensa de la fortaleza de Saqsaywaman, en 1537.

Que ya por esos años circulaban versiones no solo distintas, sino antagónicas acerca de lo sucedido y de los roles que cada miembro de la élite había jugado en las luchas, queda evidenciado por la airada reacción de parte de algunos inkas asistentes al desfile religioso, quienes interrumpieron la marcha de las andas de Chillche, para asombro de los españoles que habían organizado el desfile:

\begin{abstract}
¿No sabes que, en esos mismos días, y en esta misma plaza, cortamos treinta cabezas de españoles? ¿y que un ynca tuvo rendidas dos lanzas a dos hombres de a caballo y se las quitó de las manos, y a Gonzalo Pizarro se la hubiera de quitar si su esfuerzo y destreza no le ayudara? ¿No sabes que dejamos de hacer guerra a los españoles y desamparamos el cerro y nuestro príncipe se desterró voluntariamente y dejó su imperio a los christianos, viendo tantas y tan grandes maravillas como el Pachacámac hizo en favor y amparo dellos? ¿No sabes que matamos por esos caminos de Rímac al Cosco durante el cerco desta ciudad cerca de ochocientos españoles? ¿ Fuera bien hecho que, para honrarnos con ellas sacáramos es esta fiesta las cabezas de todos ellos y la de Juan Pizarro, que matamos allí arriba en aquella fortaleza? (Garcilaso 1962 [1617]: 108).
\end{abstract}

Se trata de proposiciones políticas altamente subversivas para la época, y autónomas, en el sentido que proponen otro lugar de enunciación, en el cual la decisión de las acciones recae en manos rebeldes (el Inka se desterró voluntariamente) y arrebata la iniciativa a los europeos (Manco fue vencido por una divinidad, Pachacámac, y no por los europeos). Nuevamente, se trata de textos que, a través de diferentes soportes (pinturas, ropajes, cabezas cercenadas) comunicaban mensajes políticos o permitían construir memorias antagónicas, sobre las cuales los españoles no solo no tenían control, sino que parecían no entender lo que enunciaban. $Y$, una vez más, se trata de textos y mensajes elaborados para actuar políticamente sobre una situación precisa y contingente; en este caso, para denunciar el apoyo que algunos inkas prestaban a los rebeldes en Vilcabamba. Para hacerlo, los distintos actores de esos acontecimientos acudieron a sus propios sistemas de registro y comunicación.

De paso, tanto la vasija de Vilcabamba como la reacción de los inkas ante la osadía de Chillche, ponen un acento en una interpretación temprana de la invasión construyendo un universo en transformación, con divinidades que ya no apoyan a los inkas.
Por el año de 1555, en la ciudad de Potosí, la sociedad española de ese importante asiento minero organizó una serie de fiestas públicas aprovechando la ocasión de que la villa había sido puesta bajo la protección de algunos santos cristianos, nombrando como patronos de la ciudad al Apóstol Santiago, a la Virgen de la Concepción y a Cristo Sacramentado. Según un testimonio muy tardío, que cita fuentes del siglo XVI, allí, en un momento dado, se presentaron "los nobles indios" quienes desfilaron y, entre varias otras representaciones, incluyeron una sobre la "ruina del imperio inga" que mostraba la "prisión injusta que hicieron [los españoles] de Atahualpa"; y también otra, la del "valeroso" Sayri Thupaq que "a la sazón vivía y molestaba a los españoles vecinos del Cuzco y de Huamanga con sangrientas guerras" (Arzáns 1965 [1735]: 98-99). Esto sugiere la contemporaneidad de esa representación respecto de la resistencia en Vilcabamba. Aunque Potosí está muy alejado del Cuzco, la breve descripción de Arzáns deja entrever que las posiciones políticas y los relatos y memorias sobre los sucesos de Vilcabamba pudieron haber circulado ampliamente por diferentes lugares de los Andes, aun en contextos de dominación colonial. Algunos estudiosos (Flores Galindo 1987: 63, Burga 2005: 409) han cuestionado la fecha de realización de estas representaciones, ya que Arzáns escribió su texto mucho después (en 1735). Para ellos, 1555 era aún muy temprano como para que las sociedades andinas hubieran podido elaborar un relato sobre la rebelión de Vilcabamba. Tal como lo muestran nuevas evidencias, como la pintura rupestre de Ollantaytambo, la vasija cerámica de Vilcabamba, y los cantares que transcribió Murúa en el Cuzco de finales del siglo xvi, parece claro que las sociedades andinas sí elaboraron muy rápidamente diversas interpretaciones acerca de la invasión europea y construyeron sus propias narrativas respecto de los inkas en Vilcabamba, por lo que la objeción señalada no parece tener más sustento que una apreciación subjetiva sobre las capacidades de reflexionar y construir relatos contingentes por parte de la élite cuzqueña o de otras poblaciones involucradas. Tampoco se conocía entonces, como sí lo sabemos hoy, que Potosí fue un importante centro de la élite inkaica vinculada a Vilcabamba (Platt \& Quisbert 2008, Cruz \& Absi 2008, Ziólkowski 2014), lo que refuerza la posibilidad de que, efectivamente, esos grupos hayan representado su versión dramatizada acerca de varios de los inkas. 


\section{DE MEMORIAS, CANTARES Y REPRESENTACIONES POSTERIORES A LA REBELIÓN}

En la Historia y genealogía de los reyes incas del Perú, de fray Martín de Murúa (manuscrito Galvin), se encuentran varios textos en quechua, que forman parte de la información que recogió el fraile mercedario respecto de algunos inkas que gobernaron en el Tawantinsuyu. Aparentemente, serían fragmentos de textos mayores que contenían los cantares históricos que se hacían sobre cada gobernante, y de los cuales varios otros cronistas ya habían dado noticias anteriormente (Cieza 1986 [1550]: cap. XI: 27, Betanzos 2015 [1551]: cap. xIv). Para los propósitos de este trabajo, lo interesante es que, junto con fragmentos de cantares sobre algunos de los inkas que gobernaron antes de la invasión europea, tales como Manco Qhapaq, Inka Roqa, Thupaq Inka Yupanqui, Wayna Qhapaq y Wasq'ar Inka, en ese manuscrito se encuentran también otros, como Manco Inka, Thupaq Amaru, Sayri Thupaq y Titu Atauchi. Este segundo grupo está compuesto por inkas y miembros de la élite cuzqueña, que vivieron en las primeras décadas del Período Colonial. Dos de esos poemas (los cantares sobre Thupaq Amaru y Sayri Thupaq, y un brevísimo texto sobre Titu Atauchi) fueron conocidos antes de la publicación del manuscrito Galvin en 2004, gracias a la publicación de un fragmento del mismo texto de Murúa transcrito por algún copista anónimo y dado a conocer por el padre Bayle en $1946 .{ }^{8}$ El que se refiere a Manco Inka, en cambio, no fue conocido sino hasta la publicación del manuscrito completo de Murúa, en 2004 (fig. 5):

\section{Viracochampa carcuscan \\ Villcapampa pirac mitmac \\ Pacampiri caypunal \\ Diego Mendez ucuchircan}

Como se fue huyendo de los españoles
a vivir a Villcabamba van
a donde fue muerto a puñaladas
por Diego Méndez mestizo español (Murúa 2004 [1590]: f. 48r).

El segundo cantar acerca de Thupaq Amaru y Sayri Thupaq es el más extenso de los que transcribió Murúa. Escrito mayormente en quechua, se inicia con la muerte del primero de esos inkas. Recordemos que su ejecución por decapitación causó profundo impacto y conmoción, tanto en la sociedad indígena como en la española (Guaman Poma 1616: fs. 450-451, véase fig. 6):

\author{
Cayna cana Van cuchuscan \\ carcan, chequiyuc amarup \\ cuncan Cusicupi Vyallean \\ Yna cunap, atun aucam \\ Yanca camachsican manta \\ Con este cuchillo fue degollado \\ el desdichado Amaro Inca \\ el Cuzco públicamente \\ por mandado del virrey \\ Don Francisco de Toledo (Murúa 2004 [1590]: f. 50v).
}

Finalmente, está el cantar sobre Titu Atauchi. ${ }^{10}$ Su inclusión en este capítulo del texto de Murúa se aclara porque fue acusado por el virrey Toledo de haber conspirado junto con los inkas refugiados en Vilcabamba (Itier 1987: 221). De este personaje se cantó lo siguiente:

\author{
Cai Vataivaci ucupin \\ Titu Atauchi tiarca \\ Yscayhuata, chay mantare \\ Cuzcuman cutimpuptina \\ Rupaina alparichirca \\ Y en esta cárcel oscura \\ estuvo Titu Atauchi Inca \\ dos años en la ciudad de Los Reyes \\ después de haber estado preso \\ en el Cuzco murió de calenturas. (Murúa 2004 [1590]: f. 50v). ${ }^{11}$
}

Lo que quiero destacar es que, además de mostrar que la costumbre de elaborar nuevos cantares históricos sobre los inkas se mantuvo probablemente al menos hasta finales del siglo XvI, esos textos evidencian que se cantaban también en el Cuzco, donde pareciera haberse construido una memoria sobre los inkas de Vilcabamba en términos no europeos, memoria que se conservaba hacia 1590, casi 20 años después de la muerte del último Inka. Al igual que los fragmentos sobre Thupaq Amaru, Sayri Thupaq y Titu Atauchi, el de Manco Inka, que recién se conoce, relata el episodio de su muerte, característica general de todos los cantares históricos inkaicos, compuestos sobre los gobernantes ya fallecidos (Schechter 1980, Martínez S., 2019). Se trataría, por lo tanto, de textos elaborados con posterioridad a los hechos relatados, reafirmando, en este caso, su composición en una fecha probable a finales del siglo XvI.

Más importante aún, todos ellos fueron compuestos desde el punto de vista de los defensores de Vilcabamba. 


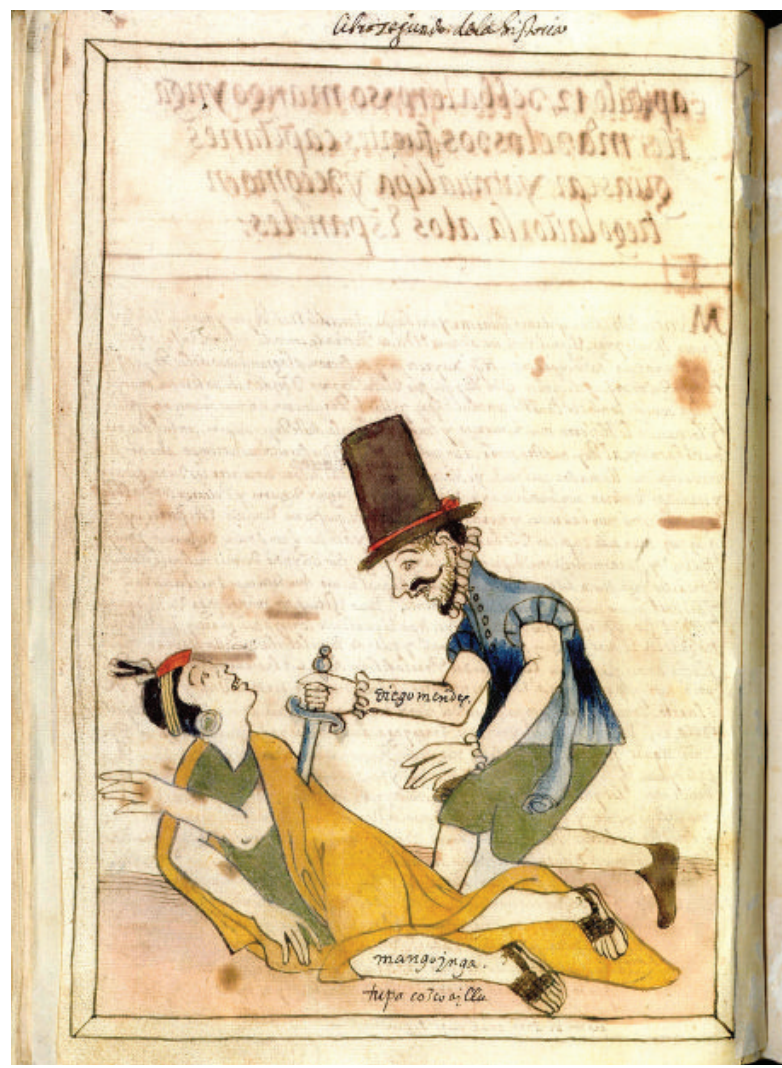

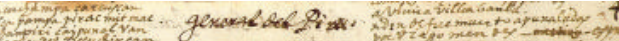 \\ capihulo,13 oclos famosos ym fan tes ycapitancs Friposocquainacapac vnorelos rrciesaesterreyno}

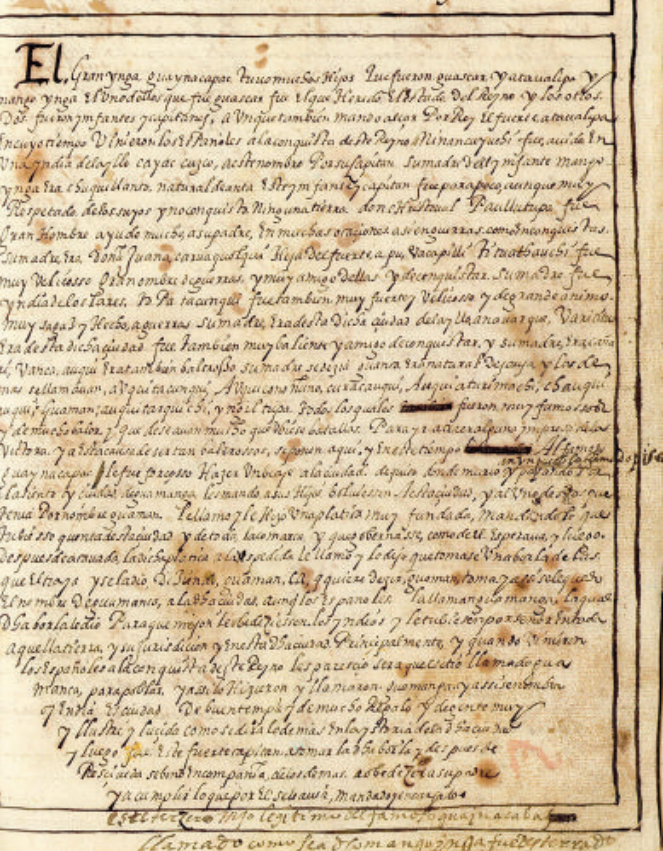

Figura 5. Asesinato de Manco Inka. En la parte superior de la foja siguiente se encuentra el texto del cantar y su traducción (Murúa 2004 [1590]: f. 47v y 48r). Figure 5. The assassination of Manco Inka. In the upper part of the following page is the text of the song and its translation (Murúa 2004 [1590]: $f .47 v$ and 48r).

Figura 6. Ejecución de Thupaq Amaru, en el Cuzco (Gua- • man Poma 1616: f. 451). Figure 6. Execution of Thupaq Amaru, in Cuzco (Guaman Poma 1616: f. 451).

Son claramente contrarios al virrey Toledo, al punto de que, en una anotación al margen del párrafo dedicado a la decapitación de Thupaq Amaru, se lee sobre ese virrey: "el que siempre quiso mal al linaje de los Incas" (Murúa 2004 [1590]: f. 50v). Debo aclarar que las traducciones, bastante libres, al parecer son del propio Murúa. Si se las compara con las transcripciones propuestas por Itier -presentes aquí en las notas al final del artículo-, se pueden advertir diferencias significativas respecto de las formas para referirse tanto a los inkas resistentes como al virrey Toledo. Mientras este último es descrito como "de los inkas su gran enemigo" (y no "el virrey Don Francisco de Toledo" como propone Murúa),

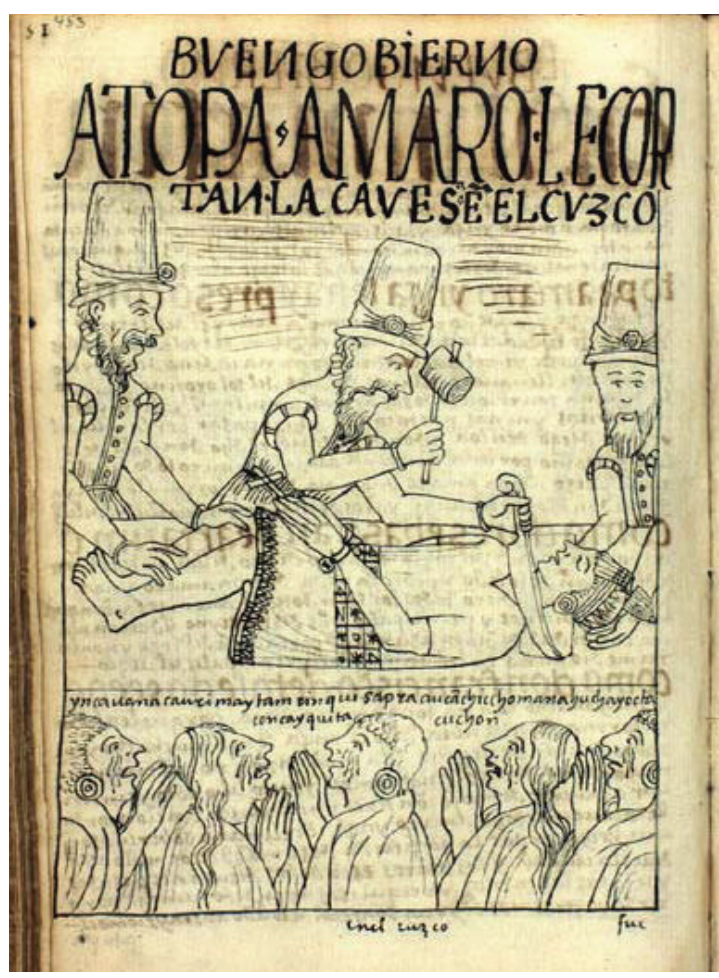


de los inkas se destaca su muerte violenta a manos de españoles (Manco "fue muerto a puñaladas" y Thupaq Amaru fue con un "cuchillo cortado"). Más aún, para acentuar la posición proclive al bando de Vilcabamba, Thupaq Amaru es descrito como "desventurado" y no como un traidor o idólatra, conceptos usados por el virrey Toledo para referirse a ellos. ${ }^{12}$ Son términos similares a los empleados en la descripción de Arzáns sobre Potosí: "prisión injusta" de Ataw Wallpa o el "valeroso" Sayry Thupaq; me parece que usan el mismo campo conceptual.

Tal como lo ha destacado Lamana $(2001,2016)$, por aquellos años la ciudad del Cuzco cobijaba a distintos bandos y alianzas. En primer lugar, los integrantes de la élite inka que apoyaban a Manco (y suponemos que varios otros señores locales de menor rango); en segundo lugar, los que seguían a Paullu Inka (a quien reconocían otros señores menores); además los cañaris, aliados ahora de los españoles y contrarios a las distintas facciones cuzqueñas; por otro lado, los bandos europeos, divididos entre pizarristas, almagristas $y$, más adelante, leales al rey. Probablemente en esta lista quedan fuera muchos otros grupos o bandos que tenían posiciones más personales o, incluso, que observaban los acontecimientos y prestaban apoyos cambiantes a unos u otros de acuerdo a las circunstancias. No es de extrañar, entonces, la existencia de esos relatos a favor de los inkas resistentes en la misma ciudad del Cuzco, aunque podemos asumir que se cantaban y representaban en contextos en los que no siempre estaban los españoles presentes. Recordemos aquí, igualmente, que al menos Paullu Inka siguió realizando las antiguas ceremonias en su palacio de Colcampata, en medio de la ciudad, tales como investir nuevos kurakas, otorgándoles el derecho a usar el asiento emblemático (las tianas); recibía -como inka- el saludo ritual o mocha que se daba a las divinidades andinas y festejaba antiguos e importantes rituales como el Inti Raymi (Lamana 2001: 33, Ziólkowski 2014: 159). Por lo tanto, podemos asumir que, efectivamente, había espacios de comunicación y circulación de narrativas andinas no controladas por los españoles que vivían allí.

Otro testimonio de los conflictos surgidos en la construcción de relatos sobre los sucesos de Vilcabamba surge del momento en el que, por encargo del virrey Toledo, se reunió a los representantes de los linajes inkaicos en el Cuzco, para ver y aprobar las pinturas acerca de la historia de los inkas, que el mismo Virrey mandó hacer para enviárselas al Rey en España. En esa ocasión, a inicios de 1572 y tal como lo relató la testigo doña María Cusi Huarcay, viuda de Sayri Thupaq y hermana de Titu Kusi Yupanqui, los representantes expresaron su oposición a que los descendientes de Paullu Inka, el Inka aliado de los españoles, fuesen pintados encima de los de su propio linaje o panaqa:

\footnotetext{
Y viendo que una hija del Paulo Inga, llamada doña Juana estava pintanda [sic] encima de la doña Maria dicha se enojo i dixo alli como se sufre que su padre de don Carlos y él estén en mas preminente lugar y su ermana siendo bastardos que mi padre e mi ermano e yo siendo legítimos y ansi se fue con otros ingas sus deudos a quexarse al Visorrei" (AGI, Lima 270 Carta de Juan de Vera al Consejo, 9-abril de 1572, en Urbano 1997: 240).
}

Hasta donde sabemos, los pintores de esos lienzos fueron gentes andinas cumpliendo instrucciones europeas (Dorta 1975). ¿En qué "preeminente lugar" fueron puestos unos y excluidos otros?, ¿"encima” implicaba más arriba, o se trataba de otra posición espacial que indicaba igualmente una mayor importancia?, ¿a qué cultura pertenecían las categorías espaciales para hacerlo, europeas o andinas? El episodio revela la coexistencia conflictiva de ambos bandos en el mismo Cuzco, así como las tensiones surgidas por la lucha para imponer uno u otro relato. Igualmente, muestra que los lenguajes y categorías a partir de los cuales se construían esos relatos también podían mostrar tensiones provenientes del empleo de sistemas culturales distintos.

\section{QEROS Y PAQCHAS. MEMORIAS TARDÍAS ACERCA DE LA VIOLENCIA Y LOS ENFRENTAMIENTOS COLONIALES}

También aparecen relatos visuales sobre batallas entre andinos y españoles, y entre distintos grupos andinos, en unos qeros -vasos de madera usados para las bebidas rituales- y paqchas, los que tenían sus paredes y superficies decoradas con complejos textos visuales. Cronológicamente, su elaboración parece haber sido más tardía que los otros textos que se han revisado hasta aquí. Nos proporcionan igualmente una valiosa comprensión acerca de cómo, distintos grupos andinos, elaboraron sus propias versiones y relatos. Más aún, permiten aproximarse al problema de la construcción de las memorias coloniales andinas, no solo las cuzqueñas, acerca de la sublevación y posterior resistencia en Vilcabamba. 


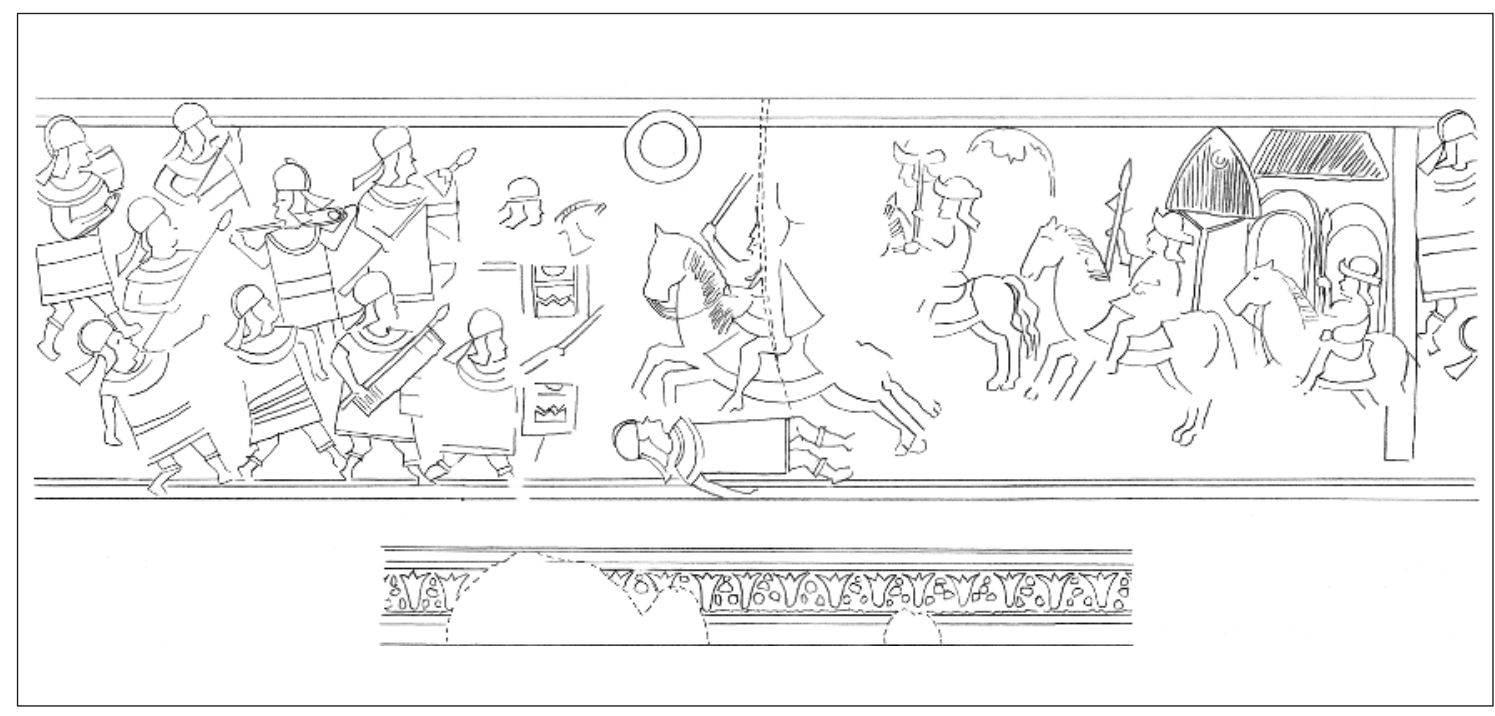

Figura 7. Qero o copa maм 7562, con escena de batalla en el Cuzco entre tropas cuzqueñas y jinetes españoles. (Dibujo: C. Yáñez, proyecto FONDECYT 1130431). Figure 7. Qero or MAM cup 7562, with battle scene in Cuzco between troops from cuzco and spanish horsemen. (Drawing: C. Yáñez, FONDECYT 1130431).

Hay consenso en asignar la factura de la mayoría de esos vasos a un Período Postoledano, iniciado probablemente a finales del siglo XVI, pero que se desarrolló con más fuerza y amplitud a lo largo de todo el siglo XVII (Rowe 1982, Cummins 2004, Martínez C. et al. 2019). Esto nos pone en una nueva situación: la de la perdurabilidad y reproducción social de las memorias andinas, puesto que siguieron circulando más de cien años después de los acontecimientos. Sin embargo, nos plantea también el problema de la construcción de esos relatos visuales: ¿a qué modelos conceptuales acudieron?, ¿desde qué lugares de enunciación fueron construidos?, ¿se impuso una única memoria o circularon varias, posiblemente antagónicas? Hay acá otro aspecto en que estos qeros tardíos son diferentes de los textos elaborados hasta antes del arribo del virrey Toledo: si bien tienen funciones de "memoria" o de autorrepresentación, parecen carecer de la urgencia de la lucha política contingente, en la que la cuestión de la legitimidad de las posiciones, de aliarse, defenderse, validarse, etc., era una cuestión estratégica. Esto puede tener implicancias en la construcción de las nuevas narrativas visuales, como lo veremos luego.

En general, la cuestión de la violencia y las batallas está profusamente representada en los qeros y paqchas. Dado que los qeros fueron un soporte privilegiado de comunicación tanto para los inkas como, más tarde, para las sociedades andinas coloniales (Cummins 2004), no es de extrañar que se encuentren algunos ejemplares con la temática del cerco del Cuzco y los enfrentamientos con europeos, aunque, como lo señala Liebscher (1986: 58), "Los motivos sobre combates entre españoles e incas, [...] son muy raros". Se trata de objetos que, como el arte rupestre y las manifestaciones músico-coreográficas, nos muestran que un aspecto importante de los intentos andinos de construir una narrativa autónoma pasaba por la producción de bienes simbólicos.

He logrado identificar cuatro ejemplares que contienen escenas vinculadas con el período de la rebelión de Manco Inka y otros dos que, propongo, también podrían estar relacionados con la narrativa sobre Vilcabamba. ${ }^{13}$ En lo que sigue, analizaré una de estas piezas, la copa мам 7562, que reúne los elementos de los otros ejemplares (fig. 7).

La escena se desarrolla en lo que parece un ambiente urbano, pues se advierten edificaciones. De acuerdo con Flores Ochoa et al. (1998: 266), se trataría del momento en que las tropas de Manco Inka cercaron a los españoles en el Sunturwasi, uno de los palacios ubicados a un costado de la plaza principal del Cuzco (fig. 8).

Este vaso muestra una escena en la que aparece, por un lado, un grupo vestido como soldados cuzqueños que está rodeado por jinetes españoles (fig. 9) y, por otro, enemigos que visten las mismas ropas y usan armas 


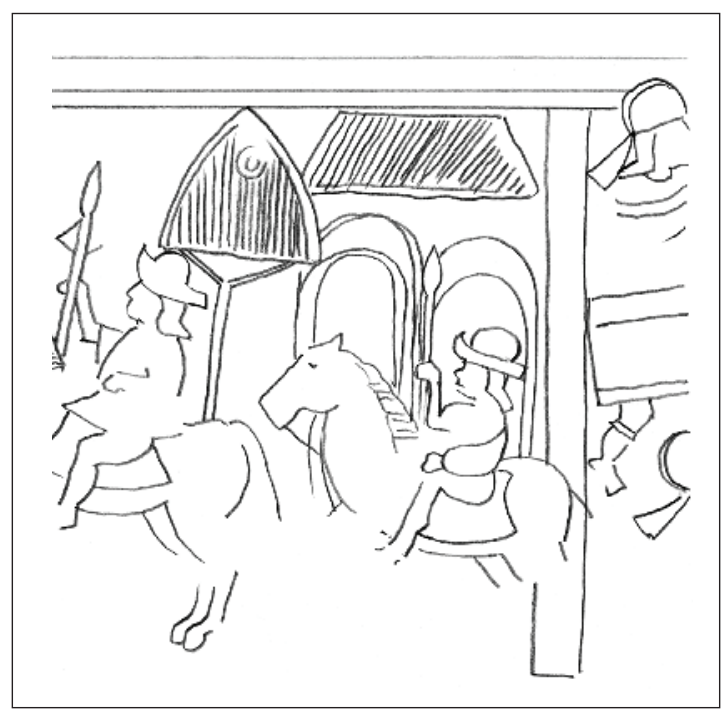

4 Figura 8. Qero Mam 7562. Detalle de un edificio que muestra un contexto urbano, posiblemente el Sunturwasi. (Dibujo: C. Yáñez, proyecto FONDECYT 1130431). Figure 8. Qero MAM 7562. Detail of a building showing an urban setting, possibly the Sunturwasi. (Drawing: C. Yáñez, FONDECYT 1130431).



Figura 9. Qero мам 7562. Detalle del grupo de jinetes españoles. El caballo que encabeza está pisando a un soldado cuzqueño derrotado. (Dibujo: C. Yáñez, proyecto FondeCYT 1130431). Figure 9. Qero mam 7562. Detail of the group of Spanish horsemen. The leading horse is stepping on a defeated cuzqueño soldier. (Drawing: C. Yáñez, FONDECYT 1130431).

similares, por lo que serían también cuzqueños como ellos. Ambos grupos están en actitud de confrontación mutua (fig. 10). Una configuración visual muy similar aparece en la lámina del códice Murúa-Galvin, en la que se representa una batalla entre Wasq'ar Inka y Quisquis, el general de Ataw Wallpa (Murúa 2004 [1590]: f. 45v. Fig. 13a). En esta construcción visual interviene también un tercer conjunto, el de entidades sagradas, el Sol y la Luna (fig. 11).
De inmediato se observa una sugerente coincidencia con la vasija cerámica de Vilcabamba. Son los mismos conjuntos de personajes y entidades participantes, por lo que la continuidad conceptual es notable. Se puede ir más allá aún. En otros qeros que muestran la expansión del Tawantinsuyu y los enfrentamientos con los chankas o los antis, también postoledanos, se advierte la misma configuración (Martínez et al. 2016). De modo que estamos ante una estructura significante, en la cual 


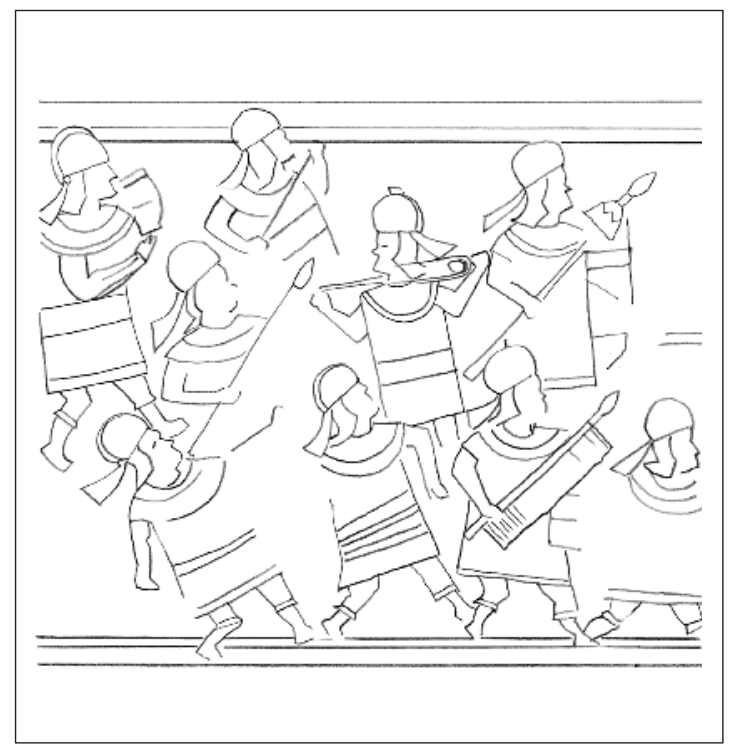

Figura 10. Qero мaм 7562, Detalle de la batalla. Al centro se advierte el enfrentamiento entre soldados cuzqueños de diferentes bandos. (Dibujo: C. Yáñez, proyecto FondeCYT 1130431). Figure 10. Qero MAM 7562. Detail of the battle. The clash between cuzqueño soldiers from different factions can be observed in the center. (Drawing: $C$. Yáñez, FONDECYT 1130431).

cada grupo presente en la escena incluye seres humanos (los combatientes de ambos bandos), objetos culturales (edificaciones, tipos de armas, vestimentas) y divinidades (Sol, Luna, aves antropomorfas que participan en las batallas), además de otros elementos que contribuyen a caracterizar simbólicamente cada conjunto (aves, animales y plantas que les son propias).

A pesar de ser muy posterior a los hechos, la construcción visual usada para representar el primer conjunto identificado, esto es, los cuzqueños, también usó modos figurativos prehispánicos presentes en la cerámica desde tiempos anteriores a la invasión europea (Fernández Baca 1989, Barraza 2012), los cuales siguieron circulando durante los siglos XVI y XVII (fig. 12). Básicamente, son los mismos modos figurativos que empleó Manco Inka cuando se hizo representar en las paredes rocosas del acceso a Ollantaytambo: la vestimenta masculina (unkus), los cascos (chukus) $)^{14} \mathrm{y}$ las lanzas o alabardas emplumadas (champi), junto con los escudos rectangulares de varillas y lana o algodón (pullkanka) y las hondas (waraqa), todo lo cual compone un tipo de configuración visual preestablecido y que fue empleado para representar a ambos bandos inkas, resistentes y aliados.

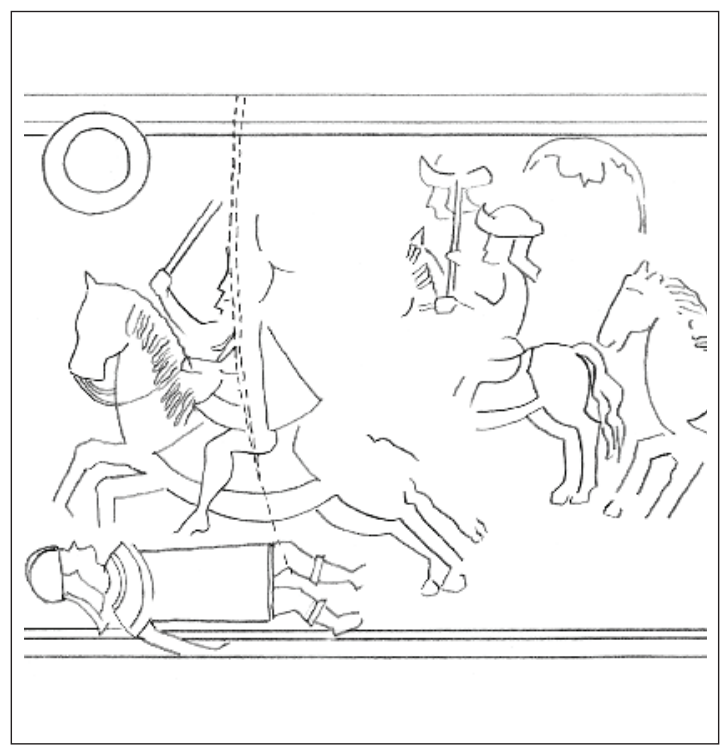

Figura 11. Qero MAM 7562, detalle con las figuras del Sol y la Luna. (Dibujo: C. Yáñez, proyecto FondecYT 1130431). Figure 11. Qero MAM 7562, detail with the Sun and the Moon. (Drawing: C. Yáñez, FONDECYT 1130431).

La identificación pareciera haber sido clara para cualquiera que hubiera tenido uno de esos vasos en sus manos o bebido en ellos. Se trata, asimismo, de la misma configuración visual que Artzi et al. (2019) identificaron en la vasija de Vilcabamba y que aparece en el texto de Murúa y en El primer nueva corónica, de Guaman Poma, de 1590 y 1616, respectivamente (figs. 13 a y b).

La construcción visual del segundo conjunto, el de los españoles, siguió igualmente el modelo construido en el siglo xvi. En los vasos analizados aquí, los europeos aparecen caracterizados como jinetes armados con espadas o lanzas. Solo en uno de esos vasos figura un personaje a pie. Se trata de un jinete desmontado que está a un lado de su caballo luchando contra un personaje cuzqueño (Flores et al. 1998: 266). Es decir, algo que ya estaba presente en las imágenes de la vasija de Vilcabamba. En estos qeros, uno de los jinetes se muestra pisando a soldados andinos derrotados (fig. 14).

Algunos autores que han estudiado la figura ecuestre en los Andes han señalado las semejanzas de la figura narrativa del jinete pisando a un vencido andino con la imagen de Santiago Mataindios. Gallardo et al. (1990) y Flores Ochoa et al. (1998: 264) proponen que, al menos uno de los jinetes españoles que aparece encabezando 


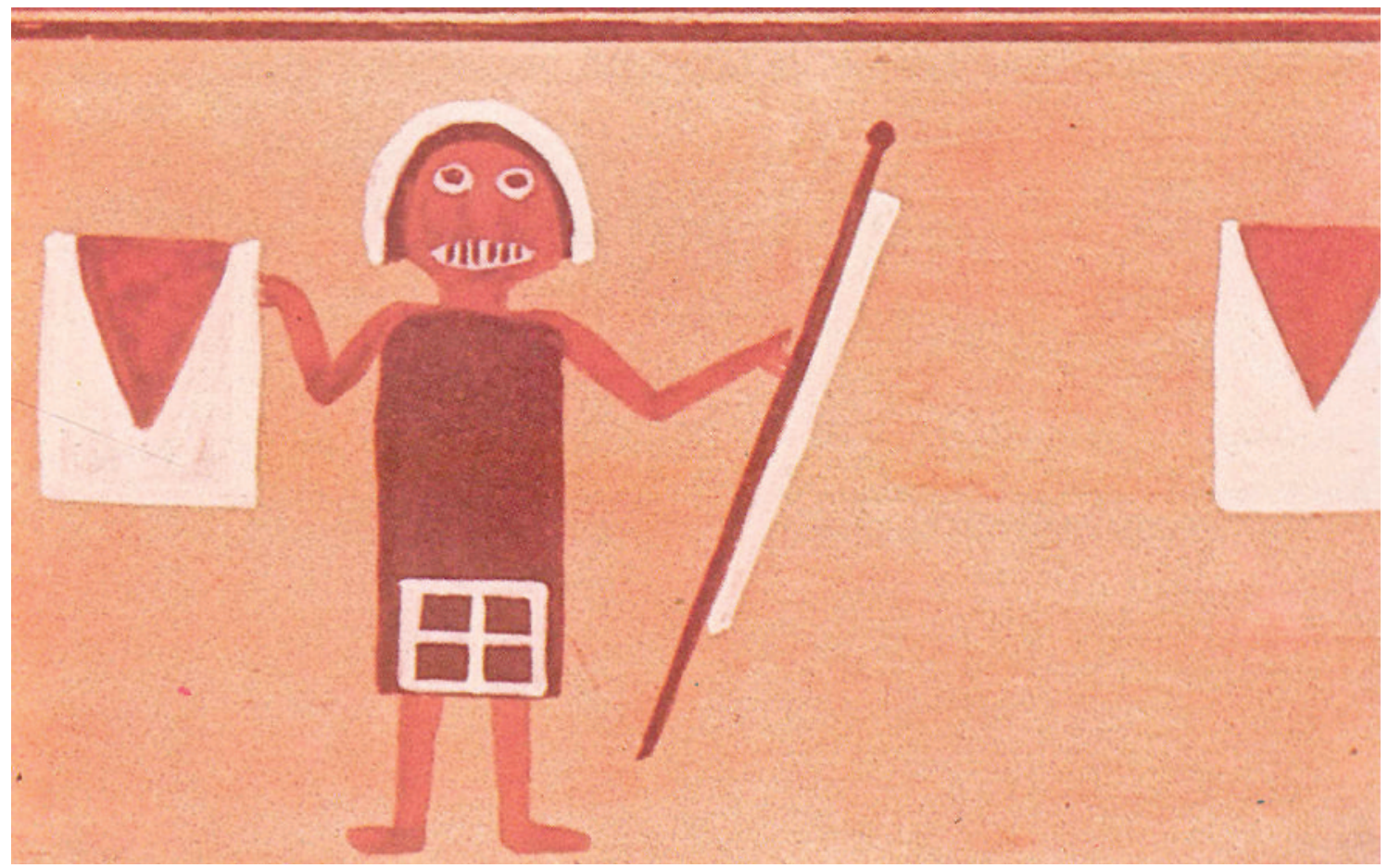

Figura 12. Cerámica inka. Configuración visual de un soldado cuzqueño con chuku-sombrero-, pullkanka-escudo- y chuqui -lanza- (en Fernández Baca 1989, fig. 302). Figure 12. Inka pottery. Visual configuration of a cuzqueño soldier with chuku-hat-, pullkanka -shield-and chuqui -spear- (in Fernández Baca 1989, fig. 302).

\section{a}

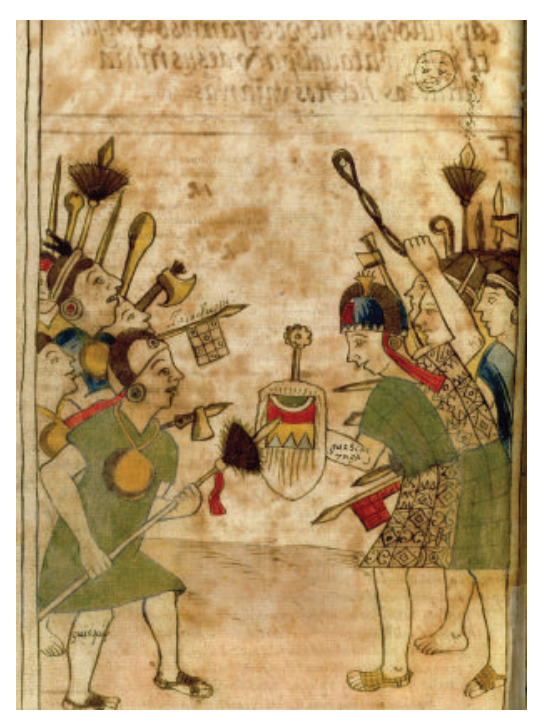

b

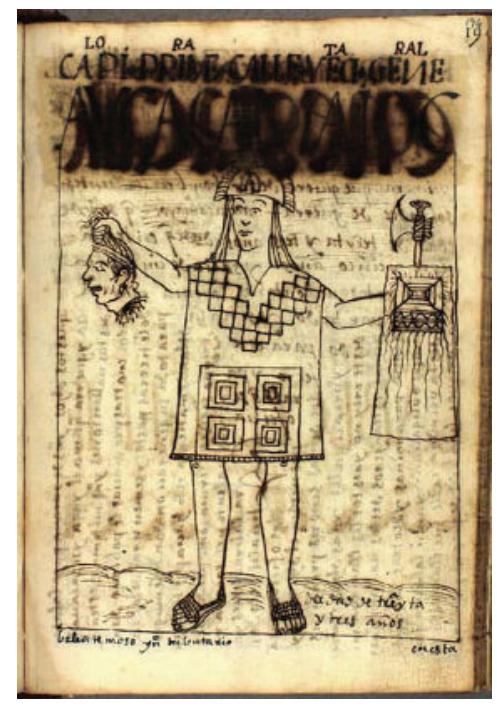

Figura 13: a) batalla entre Wasq’ar y Quisquis; ambos bandos inkas muestran las mismas armas y vestimentas (Murúa 1590: f. 45); b) Awka qamayoq, soldado cuzqueño en posición frontal con sus armas: unku, chuku, pullkanka y hacha (Guaman Poma 1616: f. 196). Figure 13: a) battle between Wasq'ar and Quisquis; both inka sides display the same weapons and clothing (Murúa 1590: $f$. 45); b) Awqa Qamayoq, cuzqueño soldier in frontal position with his weapons: unku, chuku, pullkanka and axe (Guaman Poma 1616: f. 196). 


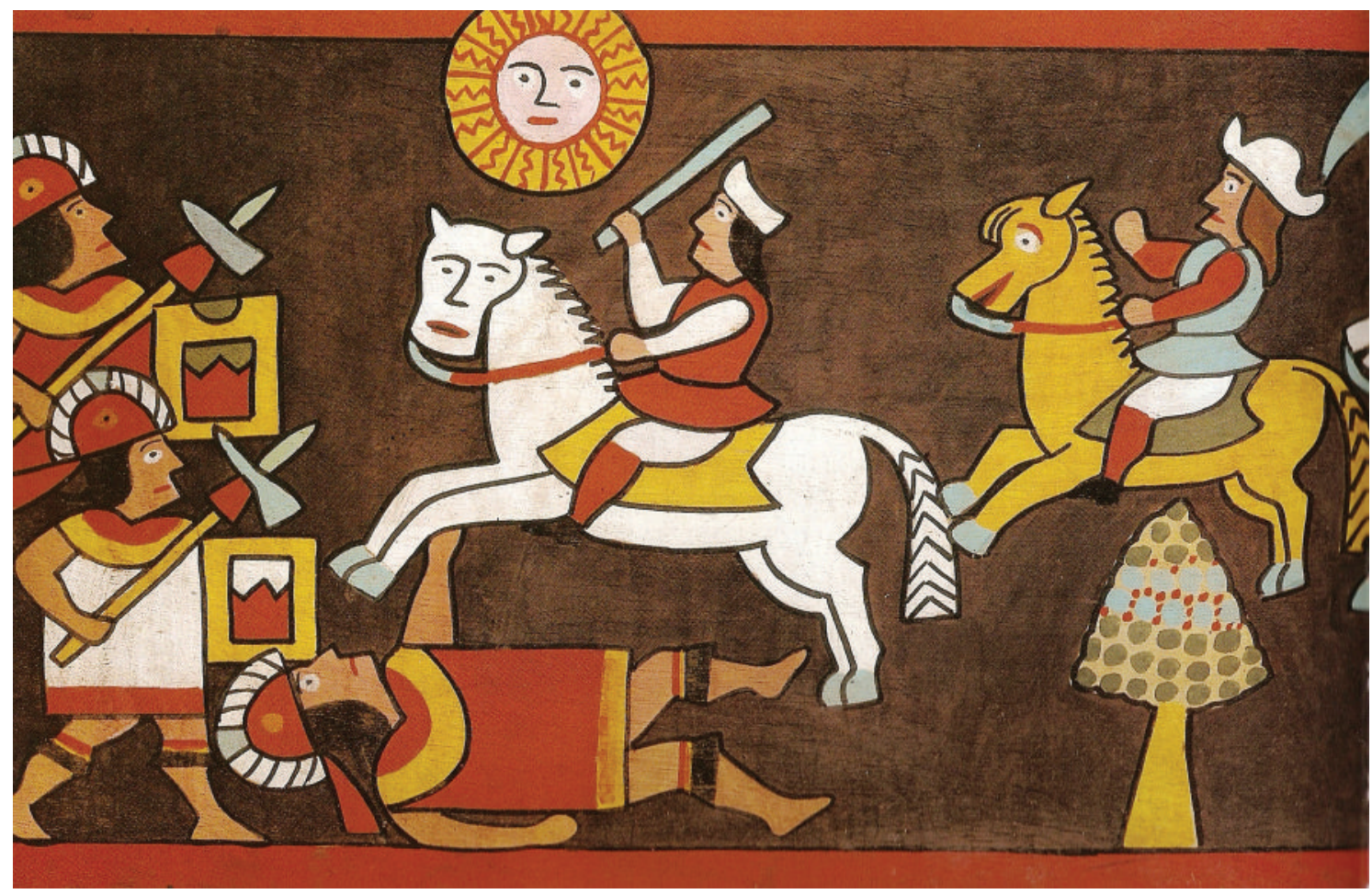

Figura 14. Posible figura de Santiago Apóstol, pisando a un soldado cuzqueño vencido. (Dibujo: E. Chávez Ballón, Museo Inka, Cuzco). Figure 14. Possible figure of St. James, stepping on a defeated cuzqueño soldier. (Drawing: E. Chávez Ballón, Inka Museum, Cuzco).

al grupo de jinetes en los cuatro vasos estudiados, representaría ese personaje concreto. En el caso específico del sitio del Cuzco por las tropas inkas sublevadas, efectivamente circuló el relato de la intervención del apóstol. Betanzos señala la aparición de un "hombre a caballo blanco todo armado y una barba blanca y larga", defendiendo al bando español y a sus aliados andinos (2015 [1551]: cap. xxxiI: 428). Guaman Poma agrega que el Apóstol Santiago se apareció en el ataque a la fortaleza de Saqsaywaman, y lo dibuja a caballo pisando el cuerpo de un soldado cuzqueño vencido (1616: f. 404).

En las lecturas contemporáneas de la imagen ecuestre se ha propuesto que el modelo inicial sería el del santo traído por los españoles y habría sido apropiado posteriormente por los andinos, prácticamente sin cambios o sin una "traducción" visual. Me parece, sin embargo, que la configuración visual que vemos en los qeros de finales del siglo xvi y a lo largo del siglo XVII, muestra una posible tensión narrativa. Si bien la iconografía de este santo lo muestra, efectivamente, como un jinete cuyo caballo está pisando a un enemigo caído, fuera moro, indio o un andino rebelde, en otros soportes andinos que circularon desde temprano en el siglo XVI, se aprecia otra construcción visual: la representación de los europeos como jinetes, siempre armados, que aparecen en grupo y luchando contra indígenas, sin figuras pisadas por los caballos. Como señalé anteriormente, se los representó más frecuentemente en grupos y sin un personaje principal (que es el caso de Santiago Apóstol), con espadas y lanzas o armas punzantes. Podríamos suponer entonces, contrario a esta configuración más difundida, que las imágenes de los qeros cuzqueños de finales del siglo XVI y del XVII se hicieron eco efectivamente del relato europeo. ¿Una memoria proclive a la versión europea?

Finalmente, el tercer conjunto está compuesto por divinidades o entidades sagradas y es más reducido en el caso del tema de la sublevación de Manco Inka. En varios de esos vasos, el Sol y la Luna, como entidades divinas, presiden varias de las batallas (fig. 11). Si Santiago Apóstol pertenece al universo religioso cristiano, el Sol y la Luna, en cambio, formarían parte de las divinidades andinas. De acuerdo con Flores Ochoa et al. (1998: 265), estas últimas estarían protegiendo a los españoles, en tanto 

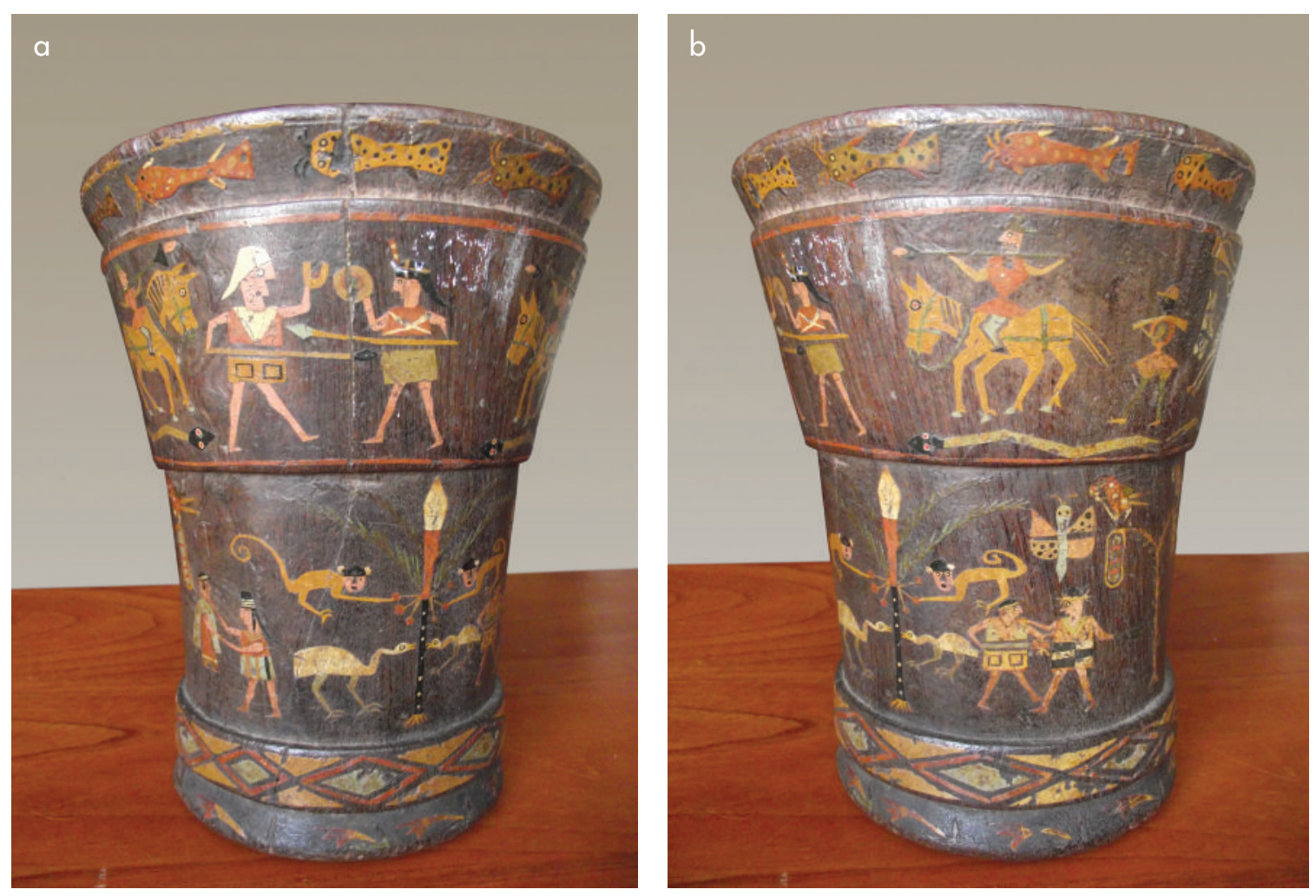

Figura 15: a-b) escenas de enfrentamientos entre andinos con presencia de jinetes españoles en el campo superior, qero MI MOмAC 2379. (Fotografía: gentileza de P. Martínez). Figure 15: $\boldsymbol{a}-\boldsymbol{b}$ ) battle scenes between andean soldiers, with spanish horsemen in the upper field, qero MI МОМАС 2379. (Photograph: courtesy of P. Martínez).

que las tropas de Manco Inka aparecerían totalmente desprotegidas. Es una lectura posible de la construcción de esta narrativa, que despojaría a los rebeldes de una protección sagrada. ¿Cómo entender esto? Hay varias posibilidades. Una primera evidenciaría nuevamente una memoria proclive -al menos- a los conquistadores, ya que los rebeldes estarían despojados de todo apoyo divino y con Santiago Apóstol venciéndolos. Sin embargo, en el episodio de las andas del cacique cañari que transcribí anteriormente, los inkas que lo increparon atribuyeron su derrota precisamente a que Pachacámac habría ayudado a los europeos y no a los cuzqueños. En esta segunda lectura, los dioses cristianos no tienen relevancia y son las divinidades andinas quienes deciden el resultado.

Sin embargo, si se observa el uso que Guaman Poma hace de estas figuras del Sol y la Luna, las posiciones más recurrentes del primero son a la derecha iconográfica y la segunda, a la izquierda (Cereceda 1987: 150, Adorno 1991: 123). Esto marcaría más bien una estructura rela- cional de la escena, también consistentemente andina colonial, en la que algunos personajes masculinos -los inkas en este caso- aparecen en el lado derecho y los personajes femeninos -españoles- al lado izquierdo. ${ }^{15}$ Cualquiera que sea la lectura correcta, se trataría de un tipo de estructuras simbólicas muy marcadas en las construcciones visuales andinas, tal como lo analizó Adorno (1991: cap. 4), lo que reafirma mi proposición de que esos relatos visuales fueron construidos, básicamente, a partir de categorías andinas y no europeas.

Hay otros vasos que podrían pertenecer al mismo ciclo narrativo acerca de la violencia de esos tiempos y que pueden aportar a nuestra comprensión de los relatos andinos de ese período. A diferencia de los que vimos anteriormente, en estos, las escenas muestran batallas entre andinos, con una presencia pasiva o insinuada de los españoles. En el primero (fig. 15), el contexto colonial y la intervención de los europeos está señalada en el campo superior por un grupo de jinetes con armas, trompetas y esclavos negros, acompañados de solda- 

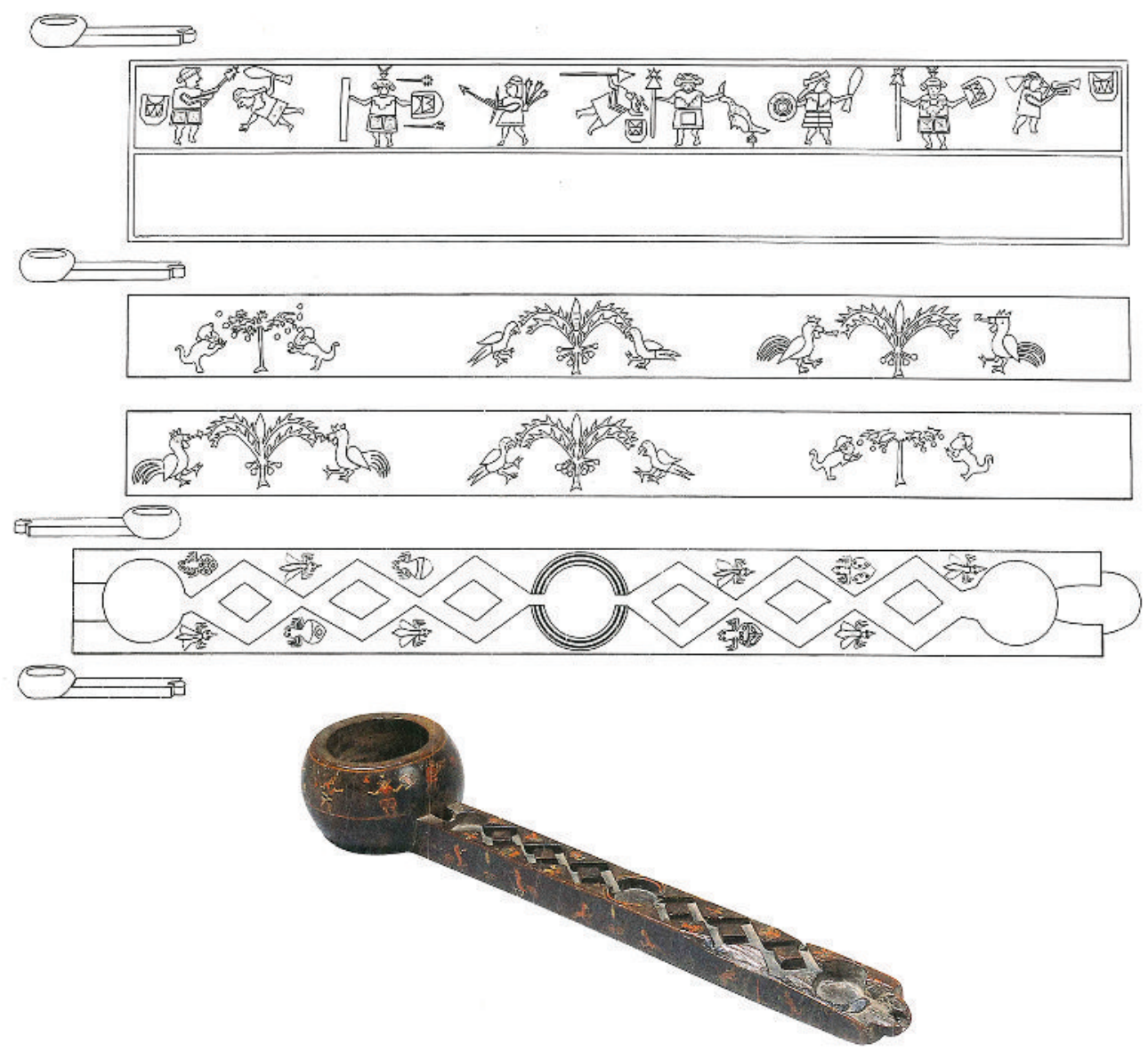

Figura 16. Paqcha MAм 7520 con escena de batalla entre inkas y otros grupos andinos. Al extremo derecho superior, un trompetista contextualiza cronológicamente la escena en el Período Colonial (Kurella \& De Castro 2013: 202). Figure 16. Paqcha MAM 7520 with battle scene between the inka and other andean groups. Top right: a trumpeter sets the scene chronologically in the Colonial Period (Kurella \& De Castro 2013: 202).

dos andinos; en una posición central se enfrentan dos personajes, ambos andinos, con trajes diferentes. En la mitad inferior del vaso, se repite un enfrentamiento entre dos andinos, vestidos igualmente con trajes y tocados distintos, que no son los mismos de la pareja superior. Es posible que se trate de dos grupos distintos, uno de los cuales está aliado a los europeos y no de cuzqueños contra otro grupo; además, las escenas ocurren en un ambiente de selva, un espacio remarcado por grandes culebras, árboles tropicales, monos y aves en sus ramas. ${ }^{16}$ ¿Posiblemente Vilcabamba, el refugio inka?

Un aspecto que puede ser relevante para este análisis es que se trata de un qero de estilo Charazani
(Martínez C. et al. 2019), es decir, no habría sido elaborado en el área cuzqueña propiamente tal, sino en el borde oriental del lago Titikaka. Esto sugiere que otras áreas más alejadas del Cuzco también elaboraron sus propios relatos, tal como lo habíamos advertido con las representaciones en Potosí y los testimonios basados en khipus de los wankas en la actual región de Ayacucho.

Quiero mostrar un último ejemplar. Se trata de una paqcha, un vaso para libaciones vinculadas a rituales agrícolas, probablemente también de estilo Charazani (fig. 16).

Aquí, un bando cuzqueño (¿rebeldes, aliados?) está claramente señalado por combatientes con unkus, 
chucus, pullkankas y lanzas. Su condición cuzqueña está destacada, además, por otras convenciones visuales, tales como las orejeras. Sus enemigos, en cambio, algunos de los cuales yacen muertos o decapitados, parecen más heterogéneos identitariamente: usan flechas y mazas, armas consideradas propias de los awqa, que eran sociedades más "salvajes", y algunos de ellos tienen el pelo largo. Hay un par de personajes, sin embargo, que llevan igualmente mazas, pero usan también escudos y tienen unkus decorados, al igual que los cuzqueños. También aquí la escena se desarrolla en un ambiente selvático, marcado en este caso por plantas tropicales, aves y monos que adornan las paredes laterales del tubo de la paqcha. No hay muchas dificultades para identificar al primer grupo de enemigos como antis, los habitantes del piedemonte andino, ya que su peinado era uno de los signos visuales más utilizados para representarlos en los qeros (Martínez C. et al. 2016). El segundo grupo puede ser más difícil de identificar. Pareciera tratarse de andinos con armas compartidas con los antis, es decir, que formarían parte de una determinada condición cultural, más cercana a los grupos de la selva que a los cuzqueños. ¿Podría tratarse, quizás, de una representación de los inkas refugiados en Vilcabamba, vista desde una enunciación de los linajes aliados a los españoles?

En esta escena hay un detalle esclarecedor que la pone en un contexto colonial, aunque no se vea ningún jinete español: en uno de sus extremos aparece un personaje tocando lo que parece una trompeta o instrumento similar, de clara procedencia europea y colonial. La presencia de este músico es muy interesante, porque sugiere una relación de enunciación entre ambos vasos: en los dos, las escenas ocurren en un ambiente de selva y las trompetas están igualmente presentes, como armas de guerra, lo que implica que ellas podrían haber sido asimiladas como equivalentes a los caracoles o quepas, que eran armas inkaicas profusamente representadas en otros qeros con escenas de batallas. El punto de enunciación es, así, muy andino. Como en la vasija de Vilcabamba, aparecen aquí insectos, moscas y arañas, todos vinculados a la relación con las divinidades y con diversos rituales, mostrando una posible variante del conjunto "divinidades" o "entidades sagradas".

\section{CONCLUSIONES}

\author{
Tu voz, tu voz, tu voz, \\ tu voz existe; \\ tu voz, tu dulce voz, \\ tu voz persiste... \\ (“Tu voz", vals peruano)
}

Cierro este trabajo con la letra de un poema de Juan Gonzalo Rose, convertido luego en un vals peruano. Siento que expresa la intención de lo que pretendí hacer aquí: acercarme a lo que se denominó las "voces andinas", una expresión -y una posición de enunciación- que posteriormente, a partir de la década de los años 90 del siglo xx, fue dejada de lado en los estudios andinos, en parte por las críticas que surgieron acerca del carácter de los textos escritos coloniales y en parte también, por la discusión que surgió sobre la colonización de los imaginarios indígenas americanos a partir de ese momento. Intentando superar las objeciones de aquellos que plantearon que era una ingenuidad pretender conocer esas voces (menos aún oírlas), una parte importante de los materiales reunidos son textos visuales y fragmentos de registros que dan cuenta del empleo de otros sistemas de comunicación: los andinos y, justamente ellos, permiten una aproximación diferente a lo que pudieron haber sido esas voces andinas en el momento en que hablaron.

¿Qué tienen en común todos estos relatos en textos andinos? Los de los qeros por un lado, pero también las representaciones músico-coreográficas, los khipus, la cerámica y el arte rupestre, por otro. ¿Cómo ayudan a entender las posiciones andinas en esos tiempos de violencia?, ¿qué (nos) dicen?

Los materiales presentados aquí proporcionan la poco usual posibilidad de acceder a discursos y narrativas andinas coloniales, disminuyendo el peso de la traducción y de las restricciones impuestas por el traspaso a la escritura alfabética. Hay que recordar que su elaboración estuvo en manos indígenas y que, si bien pudo haber sido impactada por convenciones pictóricas europeas o por la inclusión de significantes europeos, lo fundamental de la construcción de esos textos visuales responde a lenguajes y categorías propias (Martínez C. 2018). Muestran, asimismo, cómo las nuevas comunidades andinas de sentido incorporaron en sus sistemas de comunicación las cambiantes situaciones 
histórico-políticas, adecuando sus estrategias narrativas visuales para llegar a distintas audiencias. En una primera etapa, contemporánea a los sucesos, elaboraron textos políticos más contingentes, en tanto que, en las décadas posteriores, construyeron textos de memoria.

He usado el concepto de textos andinos para referirme a estos, acentuando el carácter comunicacional por sobre su materialidad (cerámicas, vasos de madera), o su localización (en una pared rocosa). Este concepto fue usado ya por Pärssinen y Kiviharju (2004) para referirse a los khipus. Tal como esos khipus, las escenas en los qeros, la cerámica, o el arte rupestre y las representaciones músico-coreográficas, dichos textos andinos poseían también sintaxis, daban cuenta de categorías de pensamiento y transmitían información que era comprendida por diferentes grupos humanos, más allá de las barreras idiomáticas planteadas por el mosaico lingüístico andino.

Los registros andinos revisados aquí muestran varios elementos que es conveniente destacar. Primero, que existieron diferentes relatos, construidos desde distintas posiciones políticas andinas. Segundo, que las sociedades andinas sí elaboraron muy rápidamente diversas interpretaciones acerca de la invasión europea y construyeron sus propias narrativas respecto de los inkas en Vilcabamba, lo que evidencia las capacidades de reflexionar y construir relatos contingentes por parte de la élite cuzqueña o de otras poblaciones involucradas. Dichas narraciones circularon contemporáneamente a la rebelión y continuaron haciéndolo al menos hasta casi un siglo después, dando cuenta de las posiciones que adoptaron unos y otros grupos y sociedades andinas frente a la rebelión, la violencia de esos tiempos y el hecho colonial. Tercero, que las poblaciones andinas usaron sus propios sistemas de registro y comunicación, con soportes adecuados a su cultura, independiente del uso y acceso que hayan tenido a los registros escritos y a escribir en ellos esos mismos relatos o partes de estos. Cuarto, que las sociedades andinas involucradas crearon nuevos significantes, articularon nuevos textos, dieron origen a nuevas comunidades de sentido, usaron viejos y nuevos significantes y los fueron resemantizando permanentemente, en un intenso proceso de semiosis andina colonial, todo ello para construir narrativas sobre la rebelión. Por último, que esos relatos transitaron por diferentes circuitos. Las pinturas rupestres fueron realizadas más allá de los espacios inkaicos; las representaciones músico-coreográficas se mostraron tanto en contextos de interacción con los españoles, aprovechando esos espacios, como en rituales o ceremonias propias de las élites, en Cuzco y otros centros coloniales; finalmente los qeros aparecían en contextos rituales, en los cuales no sabemos si los españoles tenían o no acceso, pero circularon ampliamente por todo el sur andino.

A lo largo de este trabajo he insistido reiteradamente en el carácter relativamente autónomo de estos textos. ¿Qué se puede decir de esta autonomía? La destaco, en parte, para evidenciar que sus enunciados no eran únicamente dependientes de los relatos o interpretaciones europeas, sino que empleaban básicamente sistemas conceptuales, categorías y significantes propios o que se apropiaban de otros, reinsertándolos en nuevos contextos discursivos. Además, no eran simplemente reactivos, sino propositivos, ya que ofrecen sugerencias y temas no siempre presentes en los relatos europeos de la época. Son también autónomos porque hicieron intervenir actores construidos desde un lugar andino de enunciación; porque evidencian un control del momento y del acto de la enunciación, porque eligen sus circuitos de circulación. No obstante, se trata de una autonomía relativa, porque están en un contexto de colonización en el cual se busca también producir una interlocución con el otro, con aquel que estaba imponiendo su dominación.

AgRAdecimientos Este trabajo es resultado del proyecto FONDECYT 1130431 y contó con el apoyo del Proyecto de Internacionalización UCH-1566. Agradezco a mis colegas del equipo por sus ideas y comentarios, en especial a Alejandra Vega, cuyos lúcidos aportes me permitieron orientar mejor mi propuesta. Agradezco, igualmente, a los equipos de curaduría de los Museos de América e Inka, que me permitieron estudiar las colecciones descritas aquí.

\section{NOTAS}

${ }^{1}$ Véase, por ejemplo, el relato hecho por el virrey Toledo sobre las proezas de Martín García Óñez de Loyola (AGI Lima 199 no 7) (Martínez C., 2000).

${ }^{2}$ Para lo que fueron los efectos de la translation tradition sobre los testimonios indígenas, Urton 1997.

${ }^{3}$ Estaban asentados fundamentalmente en lo que es el actual valle del Mantaro, donde también se ubica la ciudad de Xauxa. Se aliaron tempranamente a los españoles, mientras estos estaban aún en Cajamarca (Espinoza Soriano 1977, De la Puente 2011).

${ }^{4}$ Un caso similar se aprecia en los edificios del santuario de Guanacauri (agradezco a Steve Kosiba y Marco Curatola por haberme llevado hasta el sitio, hoy arqueológico). 
${ }^{5}$ Por motivos de espacio, debo dejar fuera muchos otros elementos de este texto visual. Remito al trabajo más detallado de Artzi et al. (2019).

${ }^{6}$ Los autores proporcionan dos fechados radiocarbónicos para el piso de la Unidad Arquitectónica n 5: La primera arrojó la fecha de $1593 \pm 35$ cal DC y la segunda proporcionó una fecha de $1558 \pm 35$ cal DC (Artzi et al. 2019: 159).

${ }^{7}$ Un grupo étnico ubicado en la sierra al sur del actual Ecuador, algunos de cuyos integrantes fueron llevados al Cuzco como parte de los ejércitos inkas, por Thupaq Inka Yupanqui.

${ }^{8}$ Existe un debate sobre el carácter de algunos de estos textos en quechua. Beyersdorff (1986) los presentó como testimonio de los cantares y la oralidad inka; en tanto que Itier (1987) rechaza esa atribución y propone un contenido de origen europeo, que correspondería a las políticas jesuitas de la época. Itier no parece considerar que Murúa era mercedario, y no jesuita y que ambas órdenes religiosas tenían políticas distintas hacia los indígenas. Considero que la aparición del manuscrito Galvin (publicado en 2004, véase Ossio 2004), que contiene un conjunto de otros textos en quechua sobre inkas anteriores a la invasión europea, cuestiona la proposición de Itier, ya que problematiza una supuesta intención jesuita de elaborar textos en quechua sobre inkas que gobernaron mucho tiempo antes de la llegada del virrey Toledo a los Andes, ocurrida en 1569.

${ }^{9}$ Copio aquí la transcripción propuesta por Itier (1987: 216-217), que me parece aclara mucho ambos textos, en quechua y español:

Kay ñakanawan kuchusqan

karkan chhikiyuq Amarup

kunkan, Qusqupi, uyalla,

Inkakunap hatun awqan

yaya kamachisqanmanta.

Con este cuchillo cortado

fue del desventurado Amaru

su cuello, en el Cuzco, públicamente

de los Incas su gran enemigo

Señor de su ordenado (= por su orden).

${ }^{10}$ Probablemente se trate del mismo Titu Atauchi Inka, hermano de Ataw Wallpa, al que se le atribuía haber vencido y castigado al bando español que había condenado y ejecutado al Inka, en la pretendida "batalla de la llanada de Huamachuco" (Urbano 1992: 31 y sigs.).

${ }^{11}$ Kay watay wasi ukhupiqa

T'itu Atauchi tiyarqan

iskay wata, chaymantari

Qusquman kutimpuptinña

ruphay tiya allparichirqa.

Dentro de esta cárcel

Titu Atauchi vivió

dos años, y después

al Cuzco cuando hubo vuelto ya

una calentura lo hizo padecer (y morir). (Itier 1987: 217).
${ }^{12}$ Véase AGI, Lima 199, en Martínez C., 2000.

${ }^{13}$ Los ejemplares qero мам 7562 (en forma de copa arriñonada) y paqcha MAM 7570 (publicada en Kurella \& De Castro 2013: 202), ambos del Museo de América; el qero Moмac 2379 del Museo Inka; de una pieza del Museo Inka dibujada por Chávez Ballón y de dos piezas publicadas por Flores Ochoa et al. (1998: 189 y 266).

${ }^{14}$ Los chukus también aparecen en los qeros prehispánicos y fueron pintados en el palacio que se mandó construir Sayri Thupaq cuando salió de Vilcabamba.

${ }^{15}$ En el ciclo visual de las guerras entre inkas y antis, los inkas ocupan invariablemente la derecha iconográfica en tanto que los antis aparecen siempre a la izquierda. Véase Martínez C., et al. 2016.

${ }^{16}$ Es una configuración visual ampliamente usada en otros qeros para mostrar ambientes selváticos en escenas en las que intervienen los antis o chunchos.

\section{REFERENCIAS}

Adorno, R. 1991. Guaman Poma. Literatura de resistencia en el Perú colonial. México DF: Siglo xxi.

Agustinos. 1992 [1560]. Relación de los agustinos de Huamachuco. Lima: Pontificia Universidad Católica del Perú.

Albornoz, C. 1967 [¿158...?]. Instrucción para descubrir todas las guacas del Pirú y sus camayos y haziendas. Journal de la Sociétè des Américanistes LVI (1): 7-39.

Arenas, M. \& Martínez, J. L. 2010. Del camélido al caballo: alteridad, apropiación y resignificación en el arte rupestre colonial andino. En Actas del $6^{\circ}$ Congreso de Antropología Chilena, Tomo II, pp 2067-2076. Valdivia: Colegio de Antropólogos de Chile.

Artzi, B., Nir, A. \& Fonseca, J. 2019. Los fragmentos de Vilcabamba, Perú: un testimonio iconográfico excepcional de la visión andina sobre el enfrentamiento entre indígenas y españoles. Latin American Antiquity 30 (1): 158-176. <https://doi.org/10.1017/laq.2018.76> [consultado: 19-01-2020].

Arzáns de Orsúa y Vela, B. 1965 [1735]. Historia de la Villa Imperial de Potosí. Providence: Brown University Press.

Barraza, S. 2012. Acllas y personajes emplumados en la iconografía alfarera inca: una aproximación a la ritualidad prehispánica andina. Tesis para optar el grado de Magíster en Arqueología con mención en Estudios Andinos. Pontificia Universidad Católica del Perú.

Bauer, B., Aparicio, T., Galiano, J., Halac-Higashimori, M. \& Cantarutti, G. 2014. Muerte, entierro y milagros de fray Diego Ortiz. Política y religión en Vilcabamba, s. XVI. Cuzco: Ceques.

Bauer, B., Fonseca, J. \& Aráoz, M. 2015. Vilcabamba and the archaeology of inca resistance. Los Ángeles: Cotsen Institute of Archaeology Press Monographs. 
BERENGUER, J. 2013. Unkus ajedrezados en el arte rupestre del sur del Tawantinsuyu: ¿la estrecha camiseta de la nueva servidumbre? En Las tierras altas del área Centro Sur Andina entre el 1000 y el 1600 DC, M. E. Albeck, M. Ruiz \& M. B. Cremonte, Eds., pp. 311-352. Jujuy: Universidad Nacional de Jujuy.

Betanzos, J. 2015 [1551]. Suma y narración de los Incas. En Juan de Betanzos y el Tahuantinsuyo, F. Hernández \& R. Cerrón-Palomino, Eds., pp. 107-440. Lima: Pontificia Universidad Católica del Perú.

Beyersdorff, M. 1986. Fray Martín de Murúa y el 'cantar' histórico inka. Revista Andina 8: 501-521.

Burga, M. 2005. Nacimiento de una utopía. Muerte y resurrección de los incas. Lima: Universidad Nacional Mayor de San Marcos, Universidad de Guadalajara.

Cereceda, V. 1987. Aproximaciones a una estética andina: de la belleza al tinku. En Tres reflexiones sobre el pensamiento andino, T. Bouysse-Cassagne, V. Cereceda, O. Harris \& T. Platt, Eds., pp. 133-231. La Paz: Hisbol.

Cieza de León, P. 1986 [1550]. Crónica del Perú. Lima: Fondo Editorial Universidad Católica del Perú.

Cruz, P. \& Absi, P. 2008. Cerros ardientes y huayras calladas. Potosí antes y durante el contacto. En Mina y metalurgia en los Andes del sur, desde la época prehispánica hasta el siglo XVIII, P. Cruz \& J. Vacher, Eds., pp. 91-120. Sucre: Institut de Recherche pour le Développement, Instituto Francés de Estudios Andinos.

Cummins, T. 2004. Brindis con el Inca. La abstracción andina y las imágenes coloniales de los queros. Lima: Universidad Nacional Mayor de San Marcos-Universidad Mayor de San Andrés-Embajada de los Estados Unidos de América.

De la Puente, J. 2011. Curacas 'amigos de cristianos' y 'traidores' a sus indios: a propósito de la alianza hispano-huanca. En Pueblos del hatun mayu. Historia, arqueología y antropología en el valle del Mantaro, J. L. Álvarez, C. Hurtado \& M. Perales, Comps., pp. 87-110. Lima: ConCYTEC.

Decoster, J. \& Ziólkowski, M. (Eds.). 2016. Vilcabamba entre arqueología, historia y mito. Cuzco: Centro Bartolomé de Las Casas-Centro de Estudios Andinos Universidad de Varsovia- Centro Tinku.

DorTa, E. 1975. Las pinturas que envió y trajo a España don Francisco de Toledo. Historia y Cultura 9: 67-78.

EspinozA, W. 1977. La destrucción del Imperio de los Incas. Lima: Retablo de Papel.

FALCón, V. 2013. ¿Cuándo comenzó “a existir” el arte rupestre incaico? Haucaypata 6: 49-66.

FALCón, V. 2015. Inkapintay: arte rupestre de resistencia inca a la conquista española del Tawantinsuyu. Haucaypata 10: 24-43.

Fernández BaCA, J. 1989. Motivos de ornamentación de la cerámica inca. Cuzco: CONCYTEC.

Flores Galindo, A. 1987. Buscando un inca: identidad y utopía en los Andes. Lima: Instituto de Apoyo Agrario.
Flores Ochoa, J., Kuon, E. \& Samanez, R. 1998. Qeros. Arte inka en vasos ceremoniales. Lima: Banco de Crédito del Perú.

FonsecA, J. 2016. Investigaciones arqueológicas. Resistencia andina, Espíritu Pampa, Vilcabamba, Cuzco. En Vilcabamba entre arqueología, historia y mito, J. Decoster \& M. Ziolówksi, Eds., pp. 55-61. Cuzco: Centro Bartolomé de Las Casas-Centro de Estudios Andinos Universidad de Varsovia-Centro Tinku.

Gallardo, F., Castro, V. \& Miranda, P. 1990. Jinetes sagrados en el desierto de Atacama: un estudio de arte rupestre andino. Boletín del Museo Chileno de Arte Precolombino 4: 27-56.

Garcilaso de la Vega, I. 1962 [1617]. Historia general del Perú. Lima: Biblioteca de Cultura Peruana-Universidad Nacional Mayor de San Marcos.

Garcilaso de la Vega, I. 1991 [1609]. Comentarios reales de los Incas. México DF: Fondo de Cultura Económica.

Guaman Poma de Ayala, F. [1616]. El primer nueva corónica $y$ buen gobierno. <http://www.kb.dk/permalink/2006/ poma/info/es/frontpage.htm> [consultado: 25-07-2019].

Guillén, E. 1979. Visión peruana de la conquista. Lima: Milla Batres.

Guillén, E. 2005. Ensayos de historia andina. Los incas y el trágico final del Tawantinsuyo. Volumen 2. Lima: Universidad Alas Peruanas-Academia de Historia del Perú Antiguo.

Hemming, J. 2005. La conquista de los Incas. México DF: Fondo de Cultura Económica.

Hostnig, R. 2004. Arte rupestre postcolombino de la Provincia Espinar, Cuzco, Perú. Boletín SIARB 18: 40-64.

ITIER, C. 1987. A propósito de los dos poemas en quechua de la crónica de fray Martín de Murúa. Revista Andina 9: 211-227.

Kurella, D. \& De Castro, I. (Eds.). 2013. Inka: Könige der Anden. Stuttgart: Linden-Museum Stuttgart, Lokschuppen.

Lamana, G. 2001. Definir y dominar. Los lugares grises en el Cuzco hacia 1540. Colonial Latin American Review 10 (1): 25-48.

Lamana, G. 2016. Dominación sin dominio. El encuentro incaespañol en el Perú colonial temprano. Lima: Instituto Francés de Estudios Andinos-Centro Bartolomé de Las Casas.

Liebscher, V. 1986. La iconografía de los qeros. Lima: Herrera.

Lorandi, A. M. 1988. La resistencia y rebeliones de los diaguito-calchaquí en los siglos XVI y XviI. Cuadernos de Historia 8: 99-122.

Martínez C., J. L. 2000. Voces, discursos e identidades coloniales en los Andes del siglo Xvi. En Los discursos sobre los otros (una aproximación metodológica interdisciplinaria), J. L. Martínez, Ed., pp. 127-158. Santiago: Ediciones de la Facultad de Filosofía y Humanidades, Universidad de Chile.

Martínez C., J. L. 2012. El virrey Toledo y el control de las voces andinas coloniales. Colonial Latin American Review 21 (2): $175-208$

Martínez C., J. L. \& Martínez, P. 2013. Narraciones andinas coloniales. Oralidad y visualidad en los Andes. Journal de la Société des Américanistes 99 (2): 41-81. 
Martínez C., J. L. \& M. Arenas. 2015. Iglesia en la piedra. Representación rupestre y evangelización en los Andes del Sur. En La vitalidad de las voces indígenas. El arte rupestre del contacto y en sociedades coloniales, F. Berrojalbiz, Ed., pp. 299-325. Oaxaca: Instituto de Investigaciones EstéticasUniversidad Nacional Autónoma de México.

Martínez C., J. L., DíAz, C. \& Tocornal, C. 2016. Inkas y antis, variaciones coloniales de un relato andino visual. Boletín del Museo Chileno de Arte Precolombino 21 (1): 7-23.

Martínez C., J. L. 2018. Los sistemas andinos de comunicación durante los Períodos Inkaico y Colonial: el caso de los qeros. En Interpretando huellas. Arqueología, etnohistoria y etnografía de los Andes y sus tierras bajas, M. Muñoz, Ed., pp. 447-467. Cochabamba: Khipus.

Martínez C., J. L., Tocornal, C., Díaz, C. \& Arévalo, V. 2019. A new look at the chronology of colonial andean qeros. En Inka and colonial wooden keros: recent advances in multi-disciplinary studies, E. Kaplan, Ed., Washington DC: Smithsonian Institution Scholarly Press. In press.

Martínez S., P. 2019. "Nací como lirio en el jardín": la procesión de la memoria y el cantar del Inca. En El estudio del mundo andino, M. Curatola, Ed., pp. 197-206. Lima: Pontificia Universidad Católica del Perú.

Medinacelli, X. 2014. Los inkas y las "naciones" del Collasuyu frente a la invasión española. En Ocupación inka $y$ dinámicas regionales en los Andes (siglos XV-XVII), C. Rivera, Ed., pp. 269-288. La Paz: Instituto Francés de Estudios Andinos-Plural.

Millones, L. 2007. Taki onqoy: de la enfermedad del canto a la epidemia (con las informaciones de Cristóbal de Albornoz). Santiago: DIBAM-Centro de Investigaciones Barros Arana.

Molina, C. 1968 [1553]. Conquista y población del Perú o destrucción del Perú. En Biblioteca Peruana, Primera serie III: 297-372. Lima: Editores Técnicos Asociados.

Molina, C. 2010 [1575]. Relación de las fábulas y ritos de los Incas. Madrid: Vervuert-Iberoamericana.

MurúA, M. 2004 [1590]. Historia del origen y genealogía real de los reyes ingas del Pirú, de sus hechos, costumbres, trajes y manera de gouierno, Manuscrito Galvin. Madrid: Testimonio.

Ossio, J. 2004. Códice Murúa. Historia y genealogía de los reyes incas del Perú del padre mercedario fray Martín de Murúa (códice Galvin). Madrid: Testimonio.

Pärssinen, M. \& Kiviharju, J. 2004. Textos andinos. Corpus de textos khipu incaicos y coloniales. Madrid: Instituto Iberoamericano de Finlandia-Universidad Complutense de Madrid.

PeAse, F. 1976. Los últimos Incas del Cuzco. Lima: P. L. Villanueva.

Platt, T., Bouysse-Cassagne, T. \& O. Harris. 2006. Qaraqara-Charka. Mallku, inka y rey en la provincia de Charcas (siglos XV-XVII). La Paz: Instituto Francés de Estudios Andinos-Plural editores-University of St Andrews-University of London-Interamerican Foundation-Fundación Cultural del Banco Central de Bolivia.
Platt, T. \& Quisbert, P. 2008. Tras las huellas del silencio. Potosí, los inkas y el virrey Toledo. En Mina y metalurgia en los Andes del Sur, desde la época prehispánica hasta el siglo XVIII, P. Cruz \& J. Vacher, Eds., pp. 231-277. Sucre: Institut de Recherche pour le Développement-Instituto Francés de Estudios Andinos.

Ramos, G. 1992. Política eclesiástica y extirpación de la idolatría: discursos y silencios en torno al Taqui Onqoy. Revista Andina 19:147-169.

Rowe, J. 1982 [1961]. La cronología de los vasos de madera Inca. En Arqueología del Cuzco, I. Oberti, Ed., pp. 307-343. Cuzco: Instituto Nacional de Cultura.

Roy, H. 2010. En torno al taqui oncoy: texto y contexto. Revista Andina 50: 9-39.

Roy, H. 2013. Le royaume neo-Inca de Vilcabamba (Perou, 1537-1572): étude historique et anthropologique. Tesis para obtener el grado de Doctora en Lenguas y Literaturas Románicas, Universidad de Poitiers, Poitiers.

Ruiz, M. \& Chorolque, D. 2007. Arte rupestre del pukara de Rinconada. Una larga historia visual. Jujuy: Universidad Nacional de Jujuy.

SÁNCHEZ, S. \& SICA, G. 1994. Entre águilas y halcones. Relaciones y representaciones del poder en los Andes Centro-Sur. Estudios Atacameños 11: 165-177.

SCHechter, J. 1980. El cantar histórico incaico. Revista Musical Chilena xxxiv (151): 38-60.

Trtu Cusi Yupanqui. 1992 [1570]. Instrucción a don Lope García de Castro. Lima: Pontificia Universidad Católica del Perú.

Urbano, H. 1992. Introducción a Relación de las costumbres antiguas. En Antigüedades del Perú, H. Urbano \& A. Sánchez, Eds., pp. 7-42. Madrid: Historia 16.

Urbano, H. 1997. Sexo, pinturas de los incas y taqui oncoy. Escenas de la vida cotidiana en el Cuzco del siglo xvi. Revista Andina 15 (1): 207-246.

Urton, G. 1997. De nudos a narraciones. Reconstrucción del arte de llevar registros históricos en los Andes a partir de transcripciones en español de los khipus incaicos. En Saberes y memorias en los Andes. In memoriam Thierry Saignes, T. Bouysse-Cassagne, Ed., pp. 303-323. ParísLima: CREDAL-IFEA.

ZIòLkowski, M. 2014. The mysterious death of Manco Inqa, ruler of Vilcabamba: on whose orders were the assassins acting? Estudios Latinoamericanos 33-534: 151-168. 